NBER WORKING PAPER SERIES

\title{
HOW'S YOUR GOVERNMENT? \\ INTERNATIONAL EVIDENCE LINKING \\ GOOD GOVERNMENT AND WELL-BEING
}

\author{
John F. Helliwell \\ Haifang Huang \\ Working Paper 11988 \\ http://www.nber.org/papers/w11988
NATIONAL BUREAU OF ECONOMIC RESEARCH
1050 Massachusetts Avenue
Cambridge, MA 02138
January 2006

Earlier versions of this paper were presented at the Oxford conference in honour of John Flemming, September 9-10, 2005, and the Göteborg conference on the Quality of Government, November 1719, 2005. Comments from Daron Acemoglu, Danny Kaufmann, Avner Offer, Torsten Persson, Guido Tebellini, Jan Teorell and Eric Uslaner are gratefully acknowledged. Further comments and suggestions to john.helliwell@ ubc.ca. The views expressed herein are those of the author(s) and do not necessarily reflect the views of the National Bureau of Economic Research.

(O2006 by John F. Helliwell and Haifang Huang. All rights reserved. Short sections of text, not to exceed two paragraphs, may be quoted without explicit permission provided that full credit, including $(\odot$ notice, is given to the source. 
How's Your Government? International Evidence Linking Good Government and Well-Being

John F. Helliwell and Haifang Huang

NBER Working Paper No. 11988

January 2006, Revised September 2006

JEL No. H11, I31, P52

\begin{abstract}
$\underline{\text { ABSTRACT }}$
In this paper we employ World Values Survey measures of life satisfaction as though they were direct measures of utility, and use them to evaluate alternative features and forms of government in large international samples. We find that life satisfaction is more closely linked to several World Bank measures of the quality of government than to real per capita incomes, in simple correlations and more fully specified models explaining international differences in life satisfaction. We test for differences in the relative importance of different aspects of good government, and find a hierarchy of preferences that depends on the level of development. The ability of governments to provide a trustworthy environment, and to deliver services honestly and efficiently, appears to be of paramount importance for countries with worse governance and lower incomes. The balance changes once acceptable levels of efficiency, trust and incomes are achieved, when more value is attached to building and maintaining the institutions of electoral democracy.
\end{abstract}

John F. Helliwell

Department of Economics

University of British Columbia

997-1873 East Mall

Vancouver B.C. V6T 1Z1 CANADA

and NBER

john.helliwell@ubc.ca

Haifang Huang

Department of Economics

University of British Columbia

997-1873 East Mall

Vancouver B.C. V6T 1Z1 CANADA

hhaiff@yahoo.ca 


\section{Introduction}

Adam Smith hypothesized that five factors serve to explain why some jobs are paid more than others: "First, the agreeableness or disagreeableness of the employments themselves; Secondly, the easiness and cheapness, or the difficulty and expense, of learning them; Thirdly, the constancy or inconstancy of employment in them; Fourthly, the small or great trust that must be reposed in those who exercise them; and, fifthly, probability or improbability of success in them"(Smith 1850, 45- Part I of Chapter 10 of Book 1). He argued that, in the absence of policy or other impediments to mobility, wages would tend to adjust so as to be the same for all jobs of equivalent characteristics, so that these wage differences would reflect the relative attractiveness of different employments. This analysis lies behind much of modern labour economics.

Smith's first factor- the agreeableness or disagreeableness of the job - underlies attempts to establish the value of life as reflected in wages for jobs of differing physical risks, to establish the amenity value of jobs and hence life in different locations, and to assess the value of different job characteristics, mainly disagreeable rather than agreeable features. This factor will also be the main focus of attention in this paper, although our methodology differs from previous studies, since we do not estimate compensating differentials by comparing different assumed market equilibria (as is implied by the usual equations using wages at the dependent variable). Instead, we calculate the income-equivalents of different job characteristics by comparing the effects of income and job characteristics as factors influencing life satisfaction, with the latter being treated as a direct measure of utility.

\section{Previous Approaches}

There have been many previous attempts to value non-financial aspects of jobs using wages or incomes as the dependent variable. In his survey of estimates of compensating wage variations for risk of injury or death, Viscusi (1993) notes that industry-average data were used before large samples of individual data became available in the final decades of the $20^{\text {th }}$ century. He argues that individual-level data are likely to be superior, not just because of the larger sample sizes, but because worker tastes and attributes, as well as unspecified aspects of jobs, are likely to vary across industries in ways that may be correlated with accident risks. For cross-sectional studies using individual wage or earnings data to estimate compensating differentials, there are other estimation problems. The most obvious is that posed by unmeasured differences in employee 
ability and training. More able or better-trained workers are in a position to choose jobs that produce more income and more safety, making the usual assumption that safety is a normal good. A typical estimation form is:

(1) $\ln \left(\mathrm{y}_{\mathrm{i}}\right)=\alpha-\beta \mathrm{X}_{\mathrm{i}}+\gamma \mathrm{Z}_{\mathrm{i}}+\theta \mathrm{Zu}_{\mathrm{i}}+\varepsilon_{\mathrm{i}}$

where $y_{i}$ is the earnings level for worker $i, X_{i}$ is a vector of job characteristics, applicable to worker i's job, with compensating differentials estimated by the coefficient vector $\beta$. The $Z_{i}$ are measured characteristics of worker $\mathrm{i}$, and the $\mathrm{Zu}_{\mathrm{i}}$ are unmeasured characteristics of the worker, the job, or the market environment in which the wage is being paid. The $\varepsilon_{\mathrm{i}}$ are the assumed error terms, usually taken to be iid.

To demonstrate the problem posed by un-measured differences in ability, we can start from a worker's theoretical optimization problem, and show that this unobserved ability affects both the earnings of the worker and characteristics of the chosen job:

$\operatorname{Max}_{(\mathrm{yi}, \mathrm{Xi})} \mathrm{U}\left(\mathrm{y}_{\mathrm{i}}, \mathrm{X}_{\mathrm{i}}\right)$

s.t. $\omega_{i}=y_{i}+\beta X_{i}$

$\mathrm{U}(.,$.$) is the utility function. The two arguments are income and non-financial job attributes in that$ order. Positive elements in the vector of job attributes Xi enhance utility, and vice versa. We assume that jobs differ in their characteristics, and that employees can choose a more interesting or engaging job with lower wage, or work in a less pleasant environment for a higher wage. The labour market is presumed to offer potential workers many different packages, with prices as denoted by the vector $\beta$. The budget constraint requires that the money wage and the cost (or benefit if negative) of the chosen job attributes should sum to the total earning potential of the worker, denoted as $\omega_{\mathrm{i}}$.

The solution to the maximization has to satisfy the following three-equation system including the first order condition for chosen wage, the first order condition for the chosen job attributes, and the budget constraint, in that order.

(2) $\partial \mathrm{U}\left(\mathrm{y}_{\mathrm{i}}, \mathrm{X}_{\mathrm{i}}\right) / \partial \mathrm{y}_{\mathrm{i}}=\lambda_{\mathrm{i}}$

(3) $\partial \mathrm{U}\left(\mathrm{y}_{\mathrm{i}}, \mathrm{X}_{\mathrm{i}}\right) / \partial \mathrm{X}_{\mathrm{i}}=\lambda_{\mathrm{i}} \beta$ $\omega_{\mathrm{i}}=\mathrm{y}_{\mathrm{i}}+\beta \mathrm{X}_{\mathrm{i}}$

where $\lambda_{\mathrm{i}}$ is the Lagrangian multiplier. 
Solution of this system gives optimal choice of $y_{i}$ and $X_{i}$, both of which are functions of the compensating differentials $\beta$, and the unobservable skill level $\omega_{\mathrm{i}}$

$\mathrm{y}_{\mathrm{i}}=\mathrm{y}_{\mathrm{i}}\left(\omega_{\mathrm{i}}, \beta\right) ;$ with $\partial \mathrm{y}_{\mathrm{i}} / \partial \omega_{\mathrm{i}}>0 ; \partial \mathrm{y}_{\mathrm{i}} / \partial \beta>0$

$\mathrm{X}_{\mathrm{i}}=\mathrm{X}_{\mathrm{i}}\left(\omega_{\mathrm{i}}, \beta\right) ;$ with $\partial \mathrm{X}_{\mathrm{i}} / \partial \omega_{\mathrm{i}}>0 ; \partial \mathrm{X}_{\mathrm{i}} / \partial \beta<0$

By substituting the optimal choices back into the budget constraint and moving the wage to the left hand side, we have the relation between wage and job attributes in the equilibrium that is underlying equation (1):

$y_{i}\left(\omega_{i}, \beta\right)=-\beta X_{i}\left(\omega_{i}, \beta\right)+\omega_{i}$

With cross-sectional data, the unobservable earning potential $\omega_{\mathrm{i}}$ becomes part of the error term, thus making the error term correlated with both the dependent wage variable and the job characteristics used as independent variables. The estimation of $\beta$ is going to be biased downward. For instance, suppose that the safety of the job is included among the X variables. The usual theoretical presumption is that safety is a normal good, so that workers possessing higher than average abilities will use their extra bargaining power to obtain jobs that are both safer and more highly paid. In the absence of a variable measuring ability, this behaviour would lead to an upward bias on the coefficient measuring the effects of education (assuming ability and education to be positive correlated) and a bias towards zero on the coefficients of variables measuring job safety. In the absence of variables measuring worker education and training, the downward bias in the estimation of the compensating variation for safety would probably be even greater.

Data from one of the surveys used in this paper can be used to illustrate the reality of this problem, and show also that attempts to remove the bias in the estimation of compensating differentials by allowing for the effects of education on income are likely to be insufficient. In the Canadian Equality, Security and Community (ESC) survey, for example, working respondents are asked to measure the extent to which their jobs possess five job characteristics and one workplace characteristic that are presumed (and subsequently found) to have a positive influence on job satisfaction, independent of the level of income. Each respondent is asked whether their job: allows them to make a lot of decisions on their own, requires a high level of skill, has a variety of tasks, provides enough time to get the job done, and is free of conflicting demands. These 
answers are on a four-point scale, converted to a 0 to 1 scale for the analysis presented below. Respondents are also asked, this time on a scale of 1 to 10 , to rate the level of trust that workers have in management at their workplace. Of these six factors, three have positive correlations with income (decision scope, skill and variety), while the other three have negative correlations. This pattern holds whether the correlations with income are measured individually or jointly, and occur whether or not the substantial effects of education on income are allowed for in the way depicted by equation $1^{2}$. The empirical results of Brown (1980) suggest that while omitted ability may be part of the story, it is not the only reason for earlier failures to find plausible estimates of equalizing differentials. More recently, Lang and Majumdar (2004) have developed a theoretical job search model involving jobs with both pecuniary and non-pecuniary aspects, and used it to show that in the presence of plausible frictions the resulting equilibrium allocation of workers to jobs can easily be expected to produce a cross-sectional positive simple correlation between income and (favourable) non-pecuniary job characteristics, even if workers are homogeneous.

Previous studies using Canadian income data to estimate compensating differentials include Meng (1989), Cousineau, Lacroix and Girard (1992), and Gunderson and Hyatt (2001), with the latter paper including a survey of earlier results.

\section{Using Life Satisfaction Data to Value Job Characteristics}

The econometric difficulties posed by using wage equations to identify compensating differentials suggests that it might be more promising to use subjective well-being data as a direct measure of utility, thereby permitting compensating differentials to be estimated as ratios of coefficients estimating the well-being effects of income and job characteristics. We propose an alternative to estimate compensating differentials, which is to utilize equation (2) and equation (3), the two first-order conditions that describe worker's optimal choices. We take note of the implication that the compensating differentials, $\beta$, are simply the ratios of the marginal utilities of job attributes over the marginal utility of income, i.e., $\beta=\left[\partial \mathrm{U}\left(\mathrm{y}_{\mathrm{i}}, \mathrm{X}_{\mathrm{i}}\right) / \partial \mathrm{X}_{\mathrm{i}}\right] /\left[\partial \mathrm{U}\left(\mathrm{y}_{\mathrm{i}}, \mathrm{X}_{\mathrm{i}}\right) / \partial \mathrm{y}_{\mathrm{i}}\right]$

Easy as it sounds, this approach will not be available unless utility is measured in a meaningful way, and the marginal contributions of income and job characteristics can be estimated. This is precisely where our dataset fits in. All the three surveys we are going to use for this paper include

\footnotetext{
${ }^{2}$ If a version of equation 1 is estimated using all six job characteristics and three education level variables, the sign patterns are as described in the text. Of the 'correctly' (negatively) signed job characteristics, "free of conflicting demands" is insignificant. See the Appendix for details.
} 
a question that asks respondents to report their satisfaction with life. We argue that this measure of life satisfaction, subject to some issues we shall deal with later, can be used as a direct measure of utility. The measurement of utility permits the estimation of marginal utilities, and hence of compensating differentials, while at the same time avoiding the difficulties posed by unobserved skills.

More precisely, our proposed approach is to linearize the utility function $\mathrm{U}(\mathrm{y}, \mathrm{X})$ at the equilibrium point, then to estimate the marginal contributions of job characteristics and income to life satisfaction, and finally to calculate the compensating differentials directly from these estimated coefficients, as ratios of the job characteristics coefficients to the coefficient on the (log of) income. To the extent that jobs are actually available with the characteristics in question, these ratios reflect the prevailing market prices of job attributes, usually described as compensating differentials. Essentially the same approach has been applied by Van Praag and Baarsma (2005) to estimate compensating differentials for aircraft noise in the neighbourhoods surrounding Amsterdam Airport.

In its general form, the proposed strategy is described by

$\mathrm{LS}_{\mathrm{i}}=\delta \Phi_{\mathrm{y}}\left(\mathrm{y}_{\mathrm{i}}\right)+\mu \Phi_{\mathrm{x}}\left(\mathrm{X}_{\mathrm{i}}\right)+\gamma \mathrm{Z}_{\mathrm{i}}+\varepsilon_{\mathrm{i}}$

$\beta=\mu / \delta$

Where LS is the mnemonic for life satisfaction, $\Phi_{\mathrm{y}}(\mathrm{y})$ is transformation of income, $\Phi_{\mathrm{x}}(\mathrm{X})$ is the transformation of job attributes, $Z_{\mathrm{i}}$ are all other controls. The transformations with $\Phi()$ are needed in some cases to have stable coefficients $\delta$ and $\mu$, which denote marginal utilities, across heterogeneous agents. Without any transformation, the linear specification of the utility function would imply constant marginal utility of income regardless of level, which runs counter to standard economic assumptions and many empirical results suggesting that less affluent agents derive greater utility from extra income. We acknowledge the point by using the log of income in the model instead of the level of income, therefore $\Phi_{\mathrm{y}}(\mathrm{y})=\log (\mathrm{y})$. For job attributes we adopt a simplistic view that their per unit contribution to workers is the same regardless of income or level of $\mathrm{X}$, so that $\Phi_{\mathrm{x}}\left(\mathrm{X}_{\mathrm{i}}\right)=\mathrm{X}_{\mathrm{i}}$. Finally we use $\mathrm{Z}_{\mathrm{i}}$ to control for many observed heterogeneities across agents, including, in some tests, personality differences.

The compensating differentials are calculated as ratios of coefficients. Their interpretation depends on the transformation performed on $y_{i}$ and $X_{i}$. For instance, in our empirically preferred case where income is in log form and $\mathrm{X}$ is in linear form, $\beta$ will be the log change in income (we 
convert to percentage changes in our key tables of results) that has for the average employee the same life satisfaction effect as a change of one unit in the non-financial job characteristic X.

One last point to make is that the utility function is an approximation around the equilibrium. This is because the marginal utilities, i.e., the coefficients $\delta$ and $\mu$, are likely to change if the market price changes. But for a given price, and hence a given equilibrium point, these estimated coefficients allow us to back out the price.

In the remaining sections, we describe our data and the exact empirical model used for estimating compensating differentials, present our main results, test their robustness and discuss the implications for future research.

\section{Data and Empirical Implementation}

Our three survey sources include the second wave (2002 2003) of the SSHRC-supported Equality, Security, and Community survey (ESC hereafter, it is described in more detail in Soroka et al 2006 ${ }^{3}$ ) and two Statistics Canada surveys: the 2002 post-censal Ethnic Diversity Survey (EDS), and the 2003 General Social Survey (GSS). The scope and contents of the two latter surveys are described in detail on the Statistics Canada website, and these data were accessed through the interuniversity Research Data Centre located at UBC. The surveys differ in their sample size and the nature and number of questions asked. For the results reported in this paper, we generally restrict our analysis to the working population, roughly 1700 for the second wave of the ESC, 19,300 for the EDS and 9,900 for the GSS. Fortunately, the same life satisfaction question is asked in all three surveys: "In general, how satisfied are you with your life as a whole these days, on a scale of...” The preferred ten-point scale is used for responses in the ESC and GSS, while a 5-point scale was used in the EDS. For closer comparability across surveys, we have adjusted the EDS data to an approximate 10-point scale. For the survey-ordered probit regressions we use in this paper, this rescaling has no effect on the ratios of coefficients within the same equation, and it is these ratios that provide the raw material for our calculation of compensating differentials.

\footnotetext{
${ }^{3}$ Description of the survey can also be found on the website maintained by the Centre for Research on Economic and Social Policy, the University of British Columbia, URL: http://www2.arts.ubc.ca/cresp/bk2nonsec.htm
} 
Both the ESC and the GSS asked a job satisfaction question, also on a 10-point scale. In addition, in the second wave of the ESC survey there were a number of questions relating to job characteristics, and we use these in two different ways, both to estimate a reduced-form equation in which job characteristics are used directly as part of the explanation for life satisfaction, and in the estimation of an instrumental variable for job satisfaction designed to avoid variation due to income effects, to personality differences, and to issues related to the framing of questions. The wording of the relevant questions is shown in the Appendix.

Finally, and helpfully, the GSS contains a series of questions designed to measure each respondent's psychological coping resources (Pearlin and Schooler 1978, 20). The 'mastery scale' thereby constructed may run the risk of over-correcting for the effects of pure personality differences, since the answers document the extent to which respondents feel they are in command of their circumstances ${ }^{4}$. The answers will thus be influenced not just by underlying personality traits, but also by the current range of problems exercising each respondent's coping skills. In the GSS we are also able to include measures of satisfaction in other domains of life, so that the job satisfaction coefficient should reflect only the extent to which satisfaction with the job differs from satisfaction in other domains.

Equations (4) to (6) show the basic structure of our equations for life satisfaction, which we are interpreting as a direct measure of utility. Equation (4) is designed to estimate compensating differentials for specific job characteristics. Equations (5) and (6) are for the estimation of compensating differentials for a summary measure of job satisfaction.

(4) $\mathrm{LS}_{\mathrm{i}}=\alpha+\delta_{1} \ln \left(\mathrm{y}_{\mathrm{i}}\right)+\delta_{2} \ln \left(\mathrm{y}_{\mathrm{ct}}\right)+\mu \mathrm{X}_{\mathrm{i}}+\gamma \mathrm{Z}_{\mathrm{i}}+\theta \mathrm{Zu}_{\mathrm{i}}+\varepsilon_{\mathrm{i}}$

$\mathrm{LS}_{\mathrm{i}}$ is life satisfaction for respondent $\mathrm{i}$, measured on a scale of 1 to $10, \mathrm{y}_{\mathrm{i}}$ is the level of income of the respondent's household, $\mathrm{y}_{\mathrm{ct}}$ is the average level of household income in the respondent's census tract, and the other variables are as in equation (1), except that the coefficients now measure their impact on life satisfaction rather than on wages, and the variable set is expanded to include all other determinants of life satisfaction. When we use equation (4) to estimate the value

\footnotetext{
${ }^{4}$ The index, labeled a 'mastery scale' by Statistics Canada is based on a principal component analysis of extent of agreement with the following statements: I have little control over the things that happen to me; There is really no way I can solve some of the problems I have; There is little I can do to change many of the important things in my life; I often feel helpless in dealing with the problems of life; Sometimes I feel that I'm being pushed around in life; What happens to me in the future depends mainly on me; I can do just about anything I really set my mind to do.
} 
of job characteristics, we will do so by taking the ratio of a coefficient on one of the components of the job characteristic vector $\mathrm{X}$ to $\delta_{1}$, the coefficient on log income. This matches the functional form assumptions implicit in most previous attempts to evaluate job characteristics using wage equations. It presumes that for each worker the monetary value of a change in some job characteristic is measured as a fraction of his or her income, which in turn implies that higherincome households are prepared to give up more dollars to obtain a higher level of non-financial job satisfaction. We report later on the fit and implications of alternative functional forms; finding that this simple form performs well against more complex alternatives. In any event, all of the versions we have considered give us similar basic results.

In the next two equations we limit the well-being effects of job characteristics by assuming that they flow entirely through direct measures of job satisfaction. This more restricted approach is necessary for those surveys lacking measures of job characteristics, and is also useful for comparison with the reduced-form equation (4) when the more comprehensive ESC data are being used.

(5) $\mathrm{JS}_{\mathrm{i}}=\alpha_{\mathrm{j}}+\delta_{1 \mathrm{j}} \ln \left(\mathrm{y}_{\mathrm{i}}\right)+\delta_{2 \mathrm{j}} \ln \left(\mathrm{y}_{\mathrm{ct}}\right)+\beta_{\mathrm{j}} \mathrm{X}_{\mathrm{i}}+\gamma_{\mathrm{j}} \mathrm{Z}_{\mathrm{i}}+\theta_{\mathrm{j}} \mathrm{Zu}_{\mathrm{i}}+\varepsilon_{\mathrm{ji}}$

(6) $\mathrm{LS}_{\mathrm{i}}=\alpha+\delta_{1} \ln \left(\mathrm{y}_{\mathrm{i}}\right)+\delta_{2} \ln \left(\mathrm{y}_{\mathrm{ct}}\right)+\beta_{1} \mathrm{JS}_{\mathrm{i}}+\gamma \mathrm{Z}_{\mathrm{i}}+\theta \mathrm{Zu}_{\mathrm{i}}+\varepsilon_{\mathrm{li}}$

The main challenge of estimating this system is the possibility that survey responses about job satisfaction and about life satisfaction may be influenced by the same excluded variables or are subject to similar measurement errors. All of these risks of positive bias of the estimate of the influence of job satisfaction on life satisfaction have been established in other studies, and we have found some supporting evidence in our own samples. We want to eliminate, or even overeliminate, these risks of positive bias so that our estimates of the well-being effects of job satisfaction can reasonably be thought to err on the conservative side.

Three main methods are used. The first is a two-stage instrumental estimation in which we first regress job satisfaction on a suitable set of job characteristics, and then use the predicted value to replace reported job satisfaction in equation (6). The ESC survey provides a fairly broad set of answers to particular questions about job characteristics. These are specific enough to remove the key risks attached to the job satisfaction measure, while numerous enough to span the main determinants of job satisfaction, and hence to provide an adequate information base for 
instrumental variables regression. This should serve to eliminate the risks from omitted variables, question-framing and placing issues, and two-way causality.

For this approach, we have also made an adjustment to remove the effects of income entirely from our measure of job satisfaction. In the case of the ESC, it is

(7) $\mathrm{JSn}_{\mathrm{i}}=\hat{\mathrm{JS}}_{\mathrm{i}}-\hat{\delta}_{1 j} \ln \left(y_{i}\right)$

The adjusted measure JSn in equation (7) is what we use for the ESC life satisfaction equations. The purging of income effect from job satisfaction is to make sure that, when we run regressions with job satisfaction and income on the right hand side, all the well-being effects of income flow through the income variable. JSn is to be seen as a measure of non-financial job satisfaction. The ratio of its coefficient to that of log income thus measures the log change in household income that would provide the same life satisfaction as a one-unit change in non-financial job satisfaction $^{5}$. Another issue arises with respect to the treatment of census-tract income. We might expect, following earlier results by Clark and Oswald (1996) and many others, that some measure of comparator incomes would have a significant negative effect on job satisfaction. We did include average census-tract income in regressions for job satisfaction in both surveys (see Appendix table 1), but CT income is statistically insignificant in both of them. We therefore ignore census tract income in the adjustment to define non-financial job satisfaction

The second method, where there are enough pre-determined measures of job characteristics, is to estimate the reduced form equation (4) directly, as we can do with the ESC data.

A third method is used for the GSS, where we do not have enough specific measures of job characteristics. One element of this strategy is to test the robustness of the job satisfaction effect to the inclusion of other variables likely to be correlated with both job satisfaction and life satisfaction. These include a personality variable and various measures of satisfaction in other domains of life. A second element is to use an adjusted measure of job satisfaction designed to minimize the risk that we are over-estimating the size of the compensating differential for nonfinancial job satisfaction. Since we have established that job satisfaction is positively related to

\footnotetext{
${ }^{5}$ Another possibility would be to simply leave income out of the first-stage JS equation, intending that the full reduced-form effects of income would thereby be captured in the LS equation. But, given the positive simple correlations between income and other job characteristics, this would be expected to bias downward the estimated effect of income in the LS equation, something that we are anxious to avoid. Experiments with the ESC data show this to be the case. By excluding income from the first stage regression, we obtain a smaller income effect in the LS equation, and hence a larger estimate of the compensating differential, than we get using our preferred method, although the difference is very small.
} 
income, and since we want to make sure that all the well-being effects of income flow only through the income variable itself, we have two alternative ways to define a measure of nonfinancial job satisfaction. One is to mimic what we have done for ESC by using the instrumental regression approach, recognizing that we have a rather limited set of instruments. Because the only job-specific variable in the GSS version of equation (5) is trust in co-workers, this procedure captures only the impact of trust on life satisfaction. It will be used only when we get to Table 5, where we compare alternative measures of the life satisfaction effects of trust.

The alternative procedure, which keeps more information in the measure of job satisfaction, is simply to subtract the estimated income effects from the job satisfaction data. This has the advantage of including the effects of all the additional determinants of non-financial job satisfaction, but at the expense of some possible bias caused by positive correlation between the error terms in equations (5) and (6). In this case, non-financial job satisfaction in GSS is calculated as

(7 - b) $\mathrm{JSn}_{\mathrm{i}}=\mathrm{JS}_{\mathrm{i}}-\hat{\delta}_{1 j} \ln \left(y_{i}\right)$

Figure 1 shows the presumed underlying causal schematic. We try to control for as many as possible of the direct determinants of utility, so that our estimates of the effects of income and workplace characteristics should be relatively accurate, and hence useful for constructing estimates of the income-equivalent values of various elements of workplace social capital. These control variables include gender, age, and marital status, as well as level of education, immigration and ethnic information. They also include a measure of self perceived health status (scale 1 to 5, with 5 representing the best of health), which we believe not only control for physical health, but also psychological health and some unobserved personality differences. Furthermore, we have information from all three surveys about the respondent's frequency of contacts with family members outside household, with friends, and with neighbours, and also the number of memberships (or extent of activity) in voluntary organizations. These measures are all scaled between zero and one, but they are not defined in the same way across all three surveys, so their coefficients are not strictly comparable across surveys. But they all serve the same purpose, which is to control for factors that are likely to affect life satisfaction, thereby making the coefficients on income and jobs as comparable as possible across the three surveys ${ }^{6}$. We use survey-ordered probit estimation with errors presumed to be clustered at the level of the census tract. Although the probit and linear forms give similar results for compensating differentials, the

\footnotetext{
${ }^{6}$ For more information about these controls, and how they influence life satisfaction, see Helliwell (2003, 2006) and Helliwell and Putnam (2004).
} 
probit form is perhaps more convincing, since it permits us to drop the cardinality assumption required for the linear form. In fact, the computed cut-lines for the probit suggest that there is only slightly less at stake in moving across the relatively unpopulated bottom half (in the ESC working sample, more than $90 \%$ of the respondents rank their life satisfaction at 6 or above on the 10 point scale) than the top half of the life satisfaction scale.

\section{Results}

The set of preferred equations, based on the availability of data in each survey, is contained in Table 1. Columns 1 and 2 are based on the ESC survey. In column 1 we estimate the reducedform equation (4) in which all five job characteristics and the measure of workplace trust directly enter the utility function. We later use these job characteristic coefficients, together with that of income, to calculate the compensating differentials reported in Table 4. In column 2 we present results from instrumental variables estimation of equation (6). The first stage estimation of equation (5), to provide the instruments for equation (6), can be found in Appendix Table 1.

The third column of Table 1 is based on the GSS. This equation does not have any job or workplace characteristics except for job satisfaction itself. The job satisfaction variable used is the measured value for job satisfaction with the income effect subtracted, as described in equation (7-b), using the income coefficient obtained from applying equation (5) to the GSS data. The differing treatments for the ESC and GSS data reflect the characteristics of each dataset. ESC provides a broad set of job-related information and therefore enables us to use both the reduced form and instrumental estimation. GSS does not have these variables, but it does have the mastery scale and measurements of satisfactions in other domains, thus allowing us to compensate, or perhaps even over-compensate for the risk of positive bias on the job satisfaction coefficient due to excluded variables. Table 2 shows our progress toward the final GSS equation in Table 1. Table 2 has two columns, with the only difference being the addition of the income-adjusted mastery scale in column 2 . When the domain satisfaction variables are then added, we get the final GSS equation shown in Table 1.

Our main results, the estimated compensating differentials and their standard errors, are presented in Tables 4 and 5. Table 4 includes all job attributes, Table 5 focuses on workplace trust. Since these compensating differentials are calculated as ratios of coefficients from the regressions in Table 1, their validity depends on the credibility of the variance-covariance matrix of the parameters shown in Table 1. We therefore discuss the Table 1 results before moving on to the 
compensating differentials. In particular, we address two issues. The first is the use of the mastery scale and domain satisfaction to deal with the risk of positive bias in the estimation of the job satisfaction coefficient in the GSS case. The second is the choice of income variables and the use of contextual income measures.

We deal first with personality, omitted variables and framing effects. Table 2 has two equations for the GSS, one with and one without allowing for individual-level personality differences, as embodied in the mastery scale. Because the previous literature has argued that the often-found positive relation between job satisfaction and life satisfaction might be due to the correlation with unmeasured personality differences (Arvey et al 1989, Heller et al 2002), it is important to note some of the key consequences of including individual-level personality variables.

We adjusted the mastery scale to remove its correlation with income, so as to avoid the lower income coefficient in the LS equation that would otherwise result. We had previously observed from our experiments that the effects of income on life satisfaction are much smaller when the unadjusted mastery scale is included in the equation. This may be because those with better coping personalities are more able to find and hold higher-paying positions. It may also be because those who have higher incomes, from any source, may feel better placed to deal with whatever comes their way. The coefficient on non-financial job satisfaction, on the other hand, is unchanged by addition of the mastery scale. Combined with the lower estimated effects of income, this means that making explicit allowance for individual personality differences raises rather than lowers the size of the resulting estimates of compensating variations for non-financial job satisfaction. Since we wish our estimates of these differentials to err if anything on the conservative side (because they are likely to be thought surprisingly large), we base our results on a measure of mastery scale adjusted to remove its correlation with income. This restores the income coefficient to what it was without the inclusion of the mastery scale. This makes it easier to compare the GSS results with those from the other surveys, since the ESC and the EDS do not have personality variables.

The first thing to note is that personality does indeed have a strong positive relation to life satisfaction, with the significance of the mastery scale coefficient being exceeded only by that of job satisfaction. This is consistent with numerous psychological studies, including those of identical twins raised together or apart, that show a large degree of heritability in happinessdetermining aspects of personality. It is remarkable, and encouraging, that the introduction of 
such an important variable has almost no effect on the size and significance of the coefficient on job satisfaction. Neither does it lead to significant difference in other places where personality differences have been held by sceptics to underlie some frequently observed cross-sectional correlations. For example, it has been argued that the strong positive correlation between being married and being satisfied with life exists because marriage is to a substantial degree a sorting device that enables those with outgoing and well-coping personalities to find and wed equally well-found spouses, making marriage a prize rather than a causal factor. Our results cast considerable doubt on that interpretation, as the coefficient on marriage retains its size and significance when the personality variable is included. The introduction of the mastery scale does make a difference in places where they might be expected. For example, the previously modest negative partial effects of higher education on life satisfaction (the simple correlation is strongly positive) become larger and more significantly negative, as one would expect to be the case if education provides students a chance to develop their latent coping skills. The inclusion of the mastery scale also sharpens the rise in subjective well-being after middle age, just as was previously found for health. Thus older age is more likely to lead to increased happiness for those who keep their physical health and self-perceived ability to cope with whatever life throws their way. The fact that the mastery scale itself has a negative simple correlation with age may suggest either a decline in bravado as age occurs or, alternatively or additionally, that older people see themselves as having a smaller range of options for dealing with life's exigencies.

Even after we control the personality difference with the mastery scale, there still remains in our GSS equations the possibility of framing effects, reverse causality or spill-over effects, and some remaining risk that variations in optimism through time and across individuals might skew answers to all satisfaction equations in ways not fully accounted for by the inclusion of the mastery scale. Fortunately, the GSS includes other domain satisfaction questions, each of which is likely to have a direct effect on life satisfaction but also to be subject to the same possible biases. We have therefore included the GSS responses to three key domain satisfaction questions, one related to health satisfaction, a second measuring satisfaction with the way that non-work time is spent, and the third measuring financial satisfaction. The financial satisfaction variable is purged of the influence of income, so as to keep all income effects flowing through the main income variable. These satisfaction questions were asked at the same place in the GSS as the life satisfaction and job satisfaction questions, and are scaled in exactly the same way. If framing effects were pervasive, then there would be substantial multi-collinearity among the domain satisfaction variables, and imprecise coefficients as a result. In fact, each of the domain 
satisfactions has a highly significant coefficient in the life satisfaction equation. However, including the additional domain satisfaction variables does provide extra insurance against the possibility that our job satisfaction results are driven by correlated errors, and in the process also reduces substantially the coefficient on non-financial job satisfaction. We have also undertaken experiments to ensure that our results are robust to the exclusion of groups of respondents whose answers suggest the risk of measurement error, for example, those who give nearly identical answers to all of the satisfaction questions.

The GSS life satisfaction equation in Table 1 provides our most conservative estimate of the life satisfaction effects of job satisfaction. It includes job satisfaction measured net of the Appendix Table 1 estimate of the effects of personal income (the selection of income measures is discussed shortly), other non-financial domain satisfaction answers, and the effects of personality, as represented by the mastery scale, again net of income effects. This equation thus gives us, compared to the alternatives shown in Table 2, the smallest estimate of the value, expressed in log of household income, of non-financial job satisfaction. This is given by the ratio of the job satisfaction coefficient to the coefficient on the log of household income.

We turn next to consider the alternative ways of estimating the effects of income on life satisfaction. In our previous work (e.g. Helliwell 2003), we included dummy variables for each of several income classes, so as not to constrain the all-important functional form linking income and life satisfaction. From time to time we and others have used linear approximations (which are fairly accurate over a broad range of middle-income classes in Canada) to calculate the income equivalents of other variables entering the life satisfaction equation. For the current paper, we have done further tests, and found a preferred strategy. We were interested in testing a logarithmic form as a possible substitute for the linear form for two main reasons. First, it increases comparability with earlier studies of compensating differentials. Second, if a logarithmic form should prove to be empirically defensible, it introduces in a simple way the presumed non-linearities that reduce capacity to pay as incomes fall very low, and reveal declining marginal utility of consumption as incomes get large.

We have done a number of tests of log income against more general specifications, and find the $\log$ form to be an acceptable simplification. For all three surveys, an encompassing model for life satisfaction including both household income and its logarithm $(r=.73$ between these two variables in ESC) allows the linear income variable, but not the log form, to be excluded. The 
pure linear form is also dominated in all three surveys by an equation including the income class dummy variables. When log income and the income classes are tested against one another, the choice is less clear-cut. Taking account of the saving in degrees of freedom, the log form is nonetheless preferable.

Another change to our treatment of income has been to consider various measures of contextual income levels, allowing us to test absolute versus relative income models. As a starting point, we compared personal and household income as determinants of life satisfaction reported by the survey respondent (who, in our samples, was employed, and was as likely to be female as male). We found in all three surveys that household income was the stronger of the two alternative income variables in the life satisfaction equation, with personal income being stronger in the job satisfaction equation. However, ESC and EDS life satisfaction equations that include personal and household income have significant positive coefficients on both, although the household income effect is always larger as well as more significant. In the GSS life satisfaction equation, there is no significant effect from personal income. In all three surveys, household income takes a positive coefficient given the level of personal income. This positive spill-over from the incomes of other household members implies that the empathy and income-pooling effects dominate relative income effects at this closest level of aggregation, echoing the South African results of Kingdon and Knight (2004).

In our estimation, we use personal income in our job satisfaction equations for the GSS and ESC data (EDS does not have a measure of job satisfaction). We subtract the effect of personal income to create non-financial job satisfaction, as described by equation (7) for ESC, and equation (7-b) for GSS. We do so because personal income is the stronger measure in job satisfaction and also because personal income is likely to be better than household income as a measure of the respondent's income from the job being evaluated. However, in our life satisfaction equation we include income of other household members as well, because the data show positive well-being spillovers from these other household incomes. We would like to be able to divide total household income into own income and income from other members. The compensating differential would then be estimated using personal income's coefficient. This is done in the case of ESC. The GSS data do not allow us to do this partition in a meaningful way, because GSS household income is in categories. As the result, we use only total household income in the GSS life satisfaction equation, and use its coefficient as the base for our calculation of compensating 
differentials. In order to assure comparability, we apply the second, less desirable, approach to the ESC data, and find that it gives very similar results ${ }^{7}$.

When we include the log of the average household income in the census tract, the coefficient is negative and strongly significant in all three surveys, in each case being large enough to make the life satisfaction effects of household income mostly (entirely, in the case of the GSS) relative in nature ${ }^{8}$. There are important implications of this result. ${ }^{9}$ There are other contextual effects that can be assessed with our current survey data, given the large number of census tracts represented (more than 2000 in our EDS sample, for example). We chose to include only average census-tract income in the analysis reported in this paper, since it is the only contextual variable that has a material effect on the estimated size of the compensating differentials for job characteristics. Because there is a positive correlation between respondent family income and the average family income in their census tract (e.g. +.26 in the ESC, see Appendix Table 3), and since own-family income and average income take different signs in the estimated life satisfaction equations shown in Table 1, it is important to include average income in the equation to get an unbiased estimate of the family income effect. Including average income in the census tract raises the size and the precision of our estimates of the positive life-satisfaction effects of household income. The resulting estimates of compensating differentials are thus smaller and more precise than they would otherwise be. This fits our general strategy of wishing to err if anything on the conservative side when estimating compensating differentials.

To complete our calculations of compensating differentials, we next need to develop estimates of the life satisfaction effects of workplace characteristics. The three surveys ask different questions about life in the workplace, so that some issues have to be dealt with by triangulation rather than independent parallel tests. For example, only in the GSS can we assess the likelihood that answers to workplace questions might be affected by individual-level personality differences. Only the ESC and the GSS include questions about job satisfaction, and only in the ESC is there a full set of more detailed questions about job characteristics. Fortunately, all three surveys have

\footnotetext{
${ }^{7}$ The preferred approach produces a compensating differential that is 0.68 between job satisfaction and personal income. As expected (since household income is larger than personal income, and the reference employment income is a smaller fraction thereof), using household income gives a slightly lower value, at 0.614 .

${ }^{8}$ Luttmer (2005), using UK data, shows that this general pattern of results is robust to a wider variety of sensitivity tests than can be performed with our data.

${ }^{9}$ The negative externalities implied by the negative well-being effects of rising comparator incomes and expenditure, have been noted by economists from Veblen (1899) on, including Easterlin 1995, Frank 1997, Layard 2005 and Eaton and Eswaran 2005.
} 
questions about the level of trust in the workplace, a key determinant of job satisfaction, so we can estimate the well-being effects of workplace trust for all three surveys.

Now we are ready to move on to Table 4 and Table 5 for the compensating differentials. Table 4 presents estimates for non-financial job satisfaction, the five job characteristics, and workplace trust. Table 5 presents a comparison, across surveys and across equation specifications, of the estimated compensating differentials for workplace trust. In these two tables, we also present the estimated standard errors for the compensating differentials, which are ratios of coefficients. For both ESC and GSS we calculate standard errors using the delta method and the relevant parts of the parameter variance-covariance matrix. In the case of the GSS and EDS, we are also able to use bootstrapping procedures to calculate the standard errors for the ratios as the standard deviations of the distribution of the estimated ratios from 200 bootstrap replications, multiplied by a factor of 5 in the case of $\mathrm{GSS}^{10}$.

The estimated compensating differentials for non-financial job satisfaction are very large in both the ESC and the GSS. The log income value of a one-point change in job satisfaction, on a tenpoint scale, is estimated to be .681 in the ESC and .711 in the GSS. As shown in the right-hand column in the top section of Table 4, a one-point increase on the ten-point job-satisfaction scale would have the same life satisfaction consequence as a doubling of income. These results are from our preferred equations, chosen to make all available adjustments to avoid over-statement of the effect. In the case of the ESC, the equation is based on an instrument driven from specific job characteristics, while the GSS equation includes the mastery scale and three other measures of domain satisfaction. In both cases the effects of income on job satisfaction have been removed to ensure that all income effects flow through the income variable, so that the ratio should measure the income value of change in non-financial job satisfaction.

The ESC also permits us to assess the importance of specific job characteristics, and to do so in two ways. One way is simply to estimate the reduced form, so as to reveal the net effects of job characteristics on life satisfaction. This is done in the bottom panel of Table 4. To move one-tenth of the way from the bottom to the top of the scale for different non-financial aspects of the job has an income equivalence ranging from $11 \%$ for having sufficient time to complete the assigned

\footnotetext{
${ }^{10}$ This adjustment is necessary because the GSS uses mean bootstrap weights from groups of 25 . On the use of bootstrapping in GSS, See Phillips (2004).
} 
tasks to about $20 \%$ for both skill-requirements and variety, and to more than one-third for trust in management.

The second method is to estimate the effects of job characteristics on job satisfaction, and then to calculate their effects on life satisfaction as mediated through the estimated effect of job satisfaction on life satisfaction. These two procedures (which are compared in Table 6) are not expected to give the same answers, since they are measuring interestingly different things. The biggest difference relates to the well-being consequences of having a job involving lots of decision-making. Decision-making has a significantly positive effect on job satisfaction (and hence on life satisfaction as mediated through the effect of job satisfaction in the life satisfaction equation), but in the reduced form the net effect is insignificantly negative, as shown in Tables 1 , 4 and 6. Thus the gains on the job are offset by losses on the home front. The reverse is true for skill, variety, time available and freedom from conflicting demands, all of which have greater effects in the reduced-form life satisfaction equation than where their impact is limited to that flowing through job satisfaction. This suggests positive spillovers from these job characteristics, in contrast to the negative ones from decision-making.

These results suggest some re-interpretation of the famous Whitehall study (Marmot et al 1991) showing that those at the higher levels in the UK civil service have better health outcomes. This result has been interpreted by some (e.g. Wilkinson 1996) by reference to animal studies showing worse health among those in non-dominant positions in hierarchical societies. Our evidence suggests, on the contrary, that the features of jobs that give greater life satisfaction (and by extension, better health outcomes) do not relate to control (as measured by decision-making content of the job) but instead to trustworthy management, variety, and demand for skills, features that may well be found in higher-level jobs in the Whitehall hierarchy.

As can be seen from the job satisfaction equations in Table 3, the extent of workplace trust is by far the strongest determinant of job satisfaction. This provides our key measure of social capital in the workplace.

\section{Valuing Workplace Social Capital}

Although job satisfaction has long been known to have predictive power for absenteeism, illness, and productivity, there has been less study of the role of trust and social capital as contributors to job satisfaction. In a parallel way, most studies of social capital and its effects have concentrated 
on the influence of family, friends, and community groups, with much less attention thus far paid to either the causes or consequences of workplace social capital (Halpern 2005). Given the large fraction of waking hours spent in the workplace, it should perhaps be expected that workplace social capital might be strongly linked to life satisfaction.

The ESC, GSS and EDS surveys all contain some measure or measures of workplace trust. The ESC asks about the extent to which management can be trusted in the respondent's workplace, while the GSS and EDS ask to what extent there is trust among colleagues. The resulting ratios for the values of workplace trust are shown in Table 5, and Table 4 shows the ESC-based estimates of the values of other specific job characteristics.

The social capital literature (see Halpern 2005 for a recent review) gives a central place to trust, with high levels of trust being positively related to other measures of social capital (and sometimes being used themselves as either proxy or direct measures of social capital), with causation likely to flow both ways (Putnam 2000). The well-being equations in this paper suggest that several different sorts of trust have direct effects on well-being. The fact that a variety of domain-specific trust measures have even greater well-being effects than the classical general trust responses gives us confidence that the large effects of trust on well-being are not simply due to influence of congenital optimism on both trust and reported well-being.

Another demonstration that the measured effects of trust are not simply due to personality differences is provided by the GSS job satisfaction equations in Table 3. The coefficient on the trust variable drops only from 1.02 to .95 when the mastery scale is added, and its standard error remains below .06. In addition, the preferred well-being equations in Table 1 show that trust in neighbours, trust in police and workplace trust are all independently strong determinants of respondents' subjective well-being in both the ESC and GSS. The size and significance of the workplace trust effects are even larger than for the other domains. In both surveys, inclusion of the specific trust measures renders the general trust measure insignificant.

Thus it is no surprise to see in Table 5 that there are very large compensating differentials for workplace trust. The lowest estimate we can obtain is from the GSS equation including mastery and other domains of satisfaction. We also include the GSS estimates without these variables for comparison with the ESC and EDS results, which cannot make these extra adjustments. The adjusted (lowest) GSS estimate for the ratio is 1.75 , measured as the log change in income 
corresponding to a move from the bottom to the top of workplace trust (which is converted from the 10-point scale to a zero to 1.0 scale so as to have the same scale as the other trust variables). In ESC, the mean workplace trust response is 6.5 on the ten-point scale, with a standard deviation of 2.5. The modal answer is 8 . To move up one point on the 10-point scale, using the lowest GSS estimate, has a log income value of .175 , almost $\$ 13,000$ for a modal family income of $\$ 65,000$. The right-hand column of Table 5 shows the percentage income changes matching a move from the $75^{\text {th }}$ percentile to the top rung on the measure of each survey's measure of workplace trust. In all cases, the estimates are generally four or more times as large as their estimated standard errors. The lowest estimate is for the most controlled version of the GSS equation, where a move from the $75^{\text {th }}$ percentile to the top level of workplace trust has a compensating differential equivalent to a $48 \%$ increase in household income.

\section{What Next?}

Our estimates are among the first using measures of life satisfaction to estimate compensating variations for job characteristics, and are the first we know of to provide estimates of the value of workplace trust. The estimated values of non-financial job characteristics, and especially of trust in the workplace, are very large, and remain so even when we make a number of adjustments designed to remove risks of over-estimation. Our workplace trust results are independently estimated from three different large Canadian surveys, using different samples, and different question wording. That all three surveys should show such consistently large effects convinces us of the likely importance of our results. The estimated life satisfaction effects of workplace trust are so large as to suggest that there are large unexploited gains available for trust-building activities by managers, shareholders and employees. Although current levels of workplace trust in Canada are already fairly high (almost two-thirds of employed ESC respondents rate workplace trust at 7 or better on a ten-point scale), even small improvements promise large returns, and there also a significant number of employers and employees trapped in an environment of very low trust.

Should these results be taken seriously? If trust is so important for life satisfaction, and has been found to be associated also with higher productivity, why should it not be everywhere maximized, with no need for a compensating differential? We agree that there are likely to be many trustincreasing changes in the workplace that would improve both life satisfaction and productivity, because it is probably true that the importance, fragility and complexity of workplace trust have always, and perhaps increasingly, been under-estimated by managers and by economists. 
Employees in low-trust environments, whose life satisfaction is most at risk, may simply treat low trust as a necessary part of work.

On the econometric front, some have argued that since both income and non-financial job characteristics are endogenous variables, it is not possible to interpret their coefficients. This form of objection is perhaps a carry-over from earlier studies using income as the dependent variable, and non-financial characteristics as independent variables. We are doing something quite different. We are estimating the utility function directly, and wish to include all of the relevant endogenous variables on the right-hand side. The key econometric issues in our case relate to ensuring that the specific coefficient ratios under study (the compensating variations) are not sensitive to the assumed functional structure and contents of the estimated utility function. In cases like ours, where we are finding large estimated effects for non-financial job characteristics, relative to those of income, our estimation strategy is to choose those specifications, among those with roughly equivalent predictive power, that produce high effects for income and low effects for non-financial job characteristics. More generally, we have more confidence in our results if and when they are robust to inclusion or exclusion of other variables in the estimated utility function. Our various tests on this score have thus far been encouraging.

What Next? Some have asked: Where's the optimizing economic model underlying the jobmatching behaviour depicted here? What equilibrating mechanisms are in play, and why are they producing such high values for workplace trust and other non-financial job characteristics? These are good questions, and if our results are to be believed these questions provide a fruitful agenda for future research. To go beyond the theoretical possibilities, which are likely to be driven by issues relating to information, networks, and transaction costs, will require, for estimation, workplace-based data on job characteristics and workplace trust. We do not want to pre-judge the answers, since we do not yet have sufficient workplace-based data to enable the key elements of job design and job change to be clarified in ways that explain why so many workplaces seem to offer such substantial returns from paying more attention to non-financial features of life at work. We hope that our use of life satisfaction data to estimate the possibilities has been convincing enough to encourage the next stages of research. Ideally some of this research would be based on explicit experimentation by employers with alternative ways of improving life at work. 


\section{References}

Arvey, R.D., T.J. Bouchard, N.L. Segal, and L.M. Abraham (1989) "Job Satisfaction: Environmental and Genetic Components.” Journal of Applied Psychology 74: 187-92.

Brown, Charles (1980) "Equalizing Differences in the Labor Market." Quarterly Journal of Economics 74(1): 113-34.

Clark, Andrew E., and Oswald, Andrew J. (1995) "Satisfaction and Comparison Income." Journal of Public Economics 61: 359-81.

Cousineau, Jean-Michel, Robert Lacroix, and Anne-Marie Girard (1992) "Occupational Hazard and Wage Compensating Differentials." Review of Economics and Statistics 74(1): 166-9.

Easterlin, Richard (1995) “Will Raising the Incomes of All Raise the Happiness of All?" Journal of Economic Behavior and Organization 27(1): 35-47.

Eaton, B. Curtis, and Mukesh Eswaran (2005) "The Evolution of Leisure, Consumption, and Community in the Presence of a Consumption Externality." (Paper presented at the Annual Meetings of the Canadian Economics Association)

Frank, Robert (1997) “The Frame of Reference as a Public Good.” Economic Journal 107:183247.

Gunderson, Morley, and Douglas Hyatt (2001) "Workplace Risks and Wages: Canadian Evidence from Alternative Models.” Canadian Journal of Economics 34(2): 377-95.

Halpern, David (2005) Social Capital (Cambridge: Polity Press)

Heller, Daniel, Timothy M. Judge, and David Watson (2002) "The Confounding Role of Personality and Trait Affectivity in the Relationship between Job and Life Satisfaction." Journal of Organizational Behavior 23: 815-35.

Helliwell, John F. (2003) "How's Life: Combining Individual and National Variables to Explain Subjective Well-Being." Economic Modelling 20: 331-60.

Helliwell, John F. and Robert D. Putnam (2004) "The social context of well-being” Phil Trans R. Soc Lon. B 359: 1435-46. Reprinted in F.A. Huppert, B. Kaverne and N. Baylis, eds., The Science of Well-Being. (London: Oxford University Press, 2005, 435-59).

Helliwell, John F. (2006) “Well-Being, Social Capital and Public Policy: What's New?" Economic Journal 116: C34-45.

Kingdon, Geeta G. and John Knight (2004) "Community, Comparisons and Subjective WellBeing in a Divided Society." CSAE Working Paper 2004-21 (Oxford: Centre for the Study of African Economies) 
Lang, Kevin, and Suman Majumdar (2004) "The Pricing of Job Characteristics When Markets Do Not Clear.” International Economic Review 45(4): 1111-28.

Layard, Richard (2005) Happiness: Lessons from a New Science. (London and New York: Penguin).

Luttker, Ezro F.P. (2005) "Neighbours as Negatives: Relative Earnings and Well-Being." Quarterly Journal of Economics (January): 963-1002.

Marmot, M.G., G. Davey Smitth, S. Stansfield, C. Patel, F. North and J. Head (1991) "Health Inequalities among British Civil Servants: the Whitehall Study II" Lancet 337:1387-93.

Meng, Ronald (1989) "Compensating Differences in the Canadian Labour Market." Canadian Journal of Economics 25: 413-22.

Pearlin, L.I. and C. Schooler (1978) "The Structure of Coping". Journal of Health and Social Behavior 19(1):2-21.

Phillips, Owen (2004) "On the use of bootstrap weights with Wes Var and SUDAAN". Research Data Centres Technical Bulletin 1(2): 7. (Statistics Canada No. 12-002-XIE).

Putnam, Robert D. (2000) Bowling Alone: The Collapse and Revival of American Community (New York: Simon and Schuster).

Rosen, Sherwin (1986) “The Theory of Equalizing Differentials.” Handbook of Labor Economics, Vol 1. edited by Orley Ashenfelter and Richard Layard. (North-Holland: Amsterdam) 641-92.

Smith, A. (1850) An Inquiry into the Nature and Causes of the Wealth of Nations. $\left(4^{\text {th }}\right.$ edition, edited by J. R. McCulloch, Edinburgh: Adam and Charles Black; first edition 1786)

Soroka, Stuart, John F. Helliwell and Richard Johnston (2006) "Measuring and Modelling Interpersonal Trust.” In Fiona Kay and Richard Johnston, eds., Diversity, Social Capital and the Welfare State (Vancouver: UBC Press).

Van Praag, B.M.S. and B.E. Baarsma (2005) "Using Happiness Surveys to Value Intangibles: the Case of Aircraft Noise." Economic Journal 115(January): 224-46.

Veblen, Torsten (1899) The Theory of the Leisure Class. (New York: Macmillan)

Viscusi, Kip (1993) "The Value of Risks to Life and Health.” Journal of Economic Literature 31: 1912-46.

Wilkinson, R.G. (1996) Unhealthy Societies: The Afflictions of Inequality (London: Routledge) 


\section{Figure 1: An overview of potential biases}

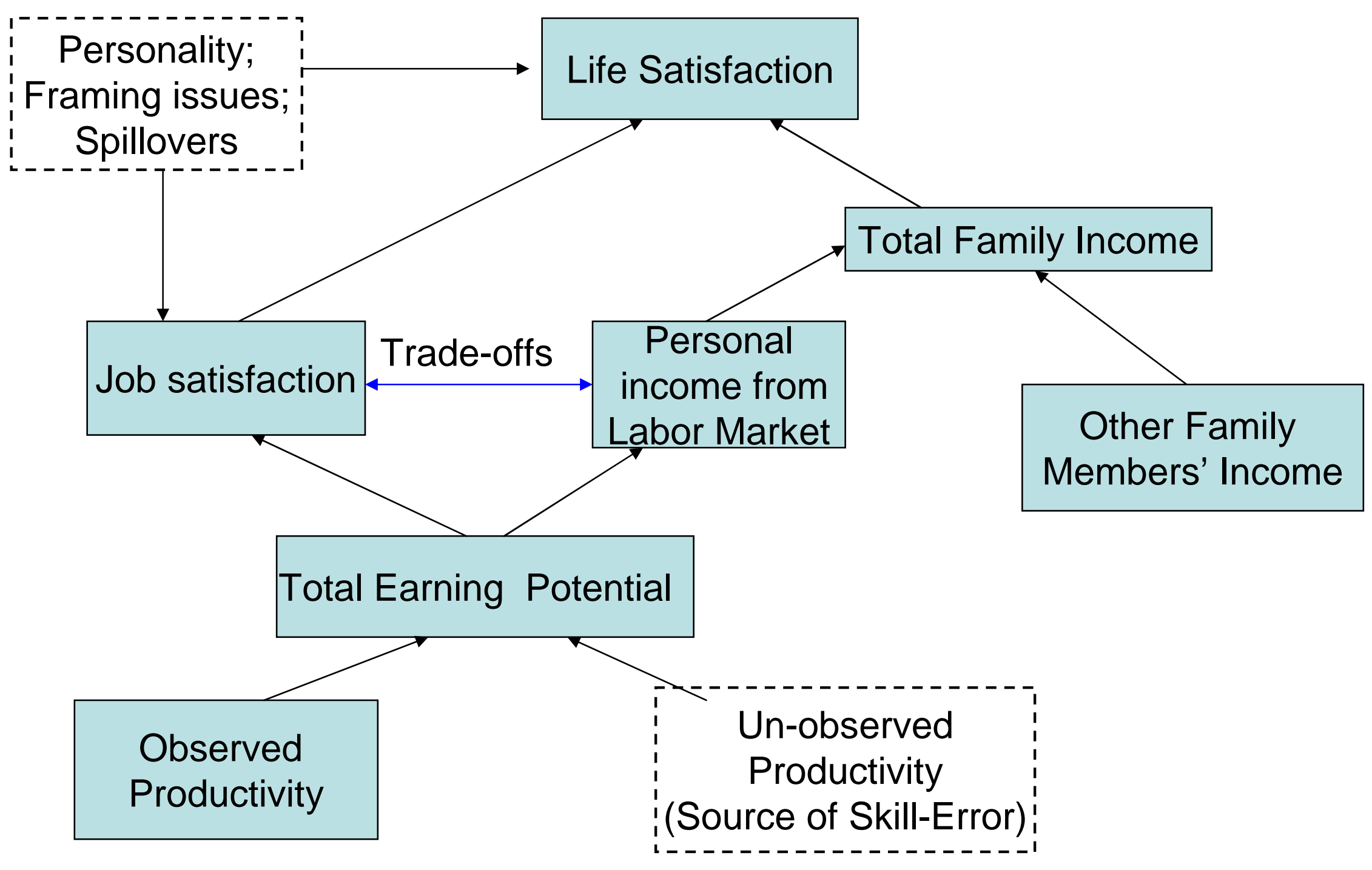


Table 1: Preferred Well-Being Equations in ESC and GSS, Estimated with Survey Ordered Probit

\begin{tabular}{|c|c|c|c|c|c|c|}
\hline \multirow{4}{*}{ D.V: Life satisfaction } & \multicolumn{4}{|c|}{ ESC Sample } & \multicolumn{2}{|c|}{ GSS Sample } \\
\hline & \multicolumn{2}{|c|}{ Number of obs $=1748$} & \multicolumn{2}{|c|}{ Number of obs $=1739$} & \multirow{2}{*}{\multicolumn{2}{|c|}{$\begin{array}{l}\text { Numberof obs }=9949 \\
F(373532)=601\end{array}$}} \\
\hline & $F(33,886)=$ & & $F(28,8$ & 8)=9.97 & & \\
\hline & Coef. & Std. Err. & Coef. & Std. Err. & Coef. & Std. Err. \\
\hline \multicolumn{3}{|l|}{ Mastery scale, with income effect subtracted (GSS only) } & & & 1.046 & 0.102 \\
\hline Job satisfaction, with income effect subtracted & & & 0.156 & 0.022 & 0.152 & 0.009 \\
\hline Log of personal income & 0.200 & 0.047 & 0.229 & 0.044 & & \\
\hline Log of other family members' income & 0.065 & 0.018 & 0.056 & 0.017 & & \\
\hline Log of total household income (GSS only) & & & & & 0.215 & 0.029 \\
\hline Log of avg. household income in census tract & -0.167 & 0.085 & -0.161 & 0.085 & -0.179 & 0.042 \\
\hline Satisfaction with health (GSS only) & & & & & 0.203 & 0.015 \\
\hline \multicolumn{3}{|l|}{ Satisfaction with the way other time spent(GSS only) } & & & 0.204 & 0.010 \\
\hline \multicolumn{3}{|c|}{ Satisfaction with financial situation, with income effect subtracted(GSS only) } & & & 0.161 & 0.010 \\
\hline Job: Makes own decision (ESC only) & $\mid-0.156$ & 0.115 & & & & \\
\hline Job: Requires skill(ESC only) & 0.340 & 0.120 & & & & \\
\hline Job: Have enough time(ESC only) & 0.210 & 0.094 & & & & \\
\hline Job: Free of conflicting demands(ESC only) & 0.139 & 0.091 & & & & \\
\hline Job: Has variety of tasks(ESC only) & 0.377 & 0.131 & & & & \\
\hline Job: Trust in management(ESC), or Trust in co-wC & 0.619 & 0.121 & & & & \\
\hline Self-perceived health status, scaled 1 to 5 & 0.266 & 0.036 & 0.253 & 0.036 & 0.037 & 0.021 \\
\hline Gender: Male & -0.126 & 0.054 & -0.110 & 0.054 & -0.099 & 0.025 \\
\hline Age Group: 25 34 & -0.291 & 0.104 & -0.261 & 0.104 & -0.172 & 0.059 \\
\hline Age Group: 35 44 & -0.157 & 0.108 & -0.096 & 0.109 & -0.270 & 0.060 \\
\hline Age Group: 45 54 & -0.197 & 0.113 & -0.166 & 0.113 & -0.298 & 0.063 \\
\hline Age Group: 55 64 & 0.081 & 0.148 & 0.082 & 0.149 & -0.265 & 0.069 \\
\hline Age Group: 65 up & 0.013 & 0.295 & -0.059 & 0.293 & -0.066 & 0.154 \\
\hline Marital Status: Married & 0.264 & 0.084 & 0.272 & 0.084 & 0.319 & 0.037 \\
\hline Marital Status: As Married & 0.345 & 0.103 & 0.384 & 0.103 & 0.214 & 0.044 \\
\hline Marital Status: Divorced & -0.092 & 0.167 & -0.091 & 0.168 & -0.119 & 0.071 \\
\hline Marital Status: Separated & -0.216 & 0.156 & -0.267 & 0.152 & -0.052 & 0.053 \\
\hline Marital Status: Widowed & -0.440 & 0.356 & -0.444 & 0.361 & -0.218 & 0.110 \\
\hline Education: High school & -0.044 & 0.117 & -0.033 & 0.117 & -0.180 & 0.059 \\
\hline Education: Between & -0.044 & 0.107 & -0.022 & 0.106 & -0.152 & 0.052 \\
\hline Education: University Degree & -0.043 & 0.111 & -0.020 & 0.110 & -0.229 & 0.057 \\
\hline Contacts with family member outside household & 0.098 & 0.096 & 0.079 & 0.096 & 0.169 & 0.044 \\
\hline Contacts with friends & 0.206 & 0.107 & 0.212 & 0.106 & 0.009 & 0.056 \\
\hline
\end{tabular}




\begin{tabular}{|c|c|c|c|c|c|c|}
\hline Contacts with neighbours & 0.001 & 0.094 & -0.013 & 0.093 & -0.036 & 0.046 \\
\hline Number of membership or extent of activity & -0.012 & 0.016 & -0.013 & 0.017 & -0.012 & 0.033 \\
\hline Trust in general & 0.070 & 0.062 & 0.057 & 0.062 & -0.073 & 0.030 \\
\hline Trust in neighbours & 0.167 & 0.084 & 0.179 & 0.083 & 0.071 & 0.017 \\
\hline Trust in police / Confidence in police & 0.254 & 0.113 & 0.298 & 0.110 & 0.237 & 0.063 \\
\hline Importance of religion & 0.147 & 0.110 & 0.132 & 0.109 & 0.097 & 0.048 \\
\hline Frequency of attending religious services & 0.002 & 0.117 & -0.024 & 0.116 & -0.061 & 0.054 \\
\hline Immigrant(GSS only) & & & & & -0.020 & 0.040 \\
\hline Ethnic: Aboriginal(GSS only) & & & & & 0.132 & 0.094 \\
\hline Ethnic: Chinese(GSS only) & & & & & -0.092 & 0.080 \\
\hline Ethnic: South Asia(GSS only) & & & & & -0.205 & 0.103 \\
\hline Ethnic: Others non-major European countrie & & & & & 0.014 & 0.041 \\
\hline Living in non-tracted area(GSS only) & & & & & -0.022 & 0.032 \\
\hline$/$ cut1 & 0.971 & 0.971 & 0.883 & 0.968 & 0.012 & 0.526 \\
\hline /cut2 & 1.096 & 0.973 & 1.009 & 0.969 & 0.541 & 0.505 \\
\hline /cut3 & 1.224 & 0.976 & 1.136 & 0.971 & 1.036 & 0.500 \\
\hline /cut4 & 1.434 & 0.973 & 1.344 & 0.968 & 1.364 & 0.500 \\
\hline /cut5 & 1.945 & 0.977 & 1.842 & 0.970 & 2.303 & 0.499 \\
\hline /cut6 & 2.265 & 0.977 & 2.162 & 0.971 & 2.883 & 0.501 \\
\hline /cut7 & 2.949 & 0.979 & 2.843 & 0.972 & 3.933 & 0.504 \\
\hline /cut8 & 3.866 & 0.983 & 3.754 & 0.975 & 5.209 & 0.507 \\
\hline /cut9 & 4.481 & 0.984 & 4.370 & 0.977 & 6.135 & 0.510 \\
\hline
\end{tabular}

* All satisfaction variables are in the scale of 1 10, health is in a 5 point scale. Mastery, job characteristics, family, friends, neighbours,

trust and religious measures are recorded to be within the scale of $0 \sim 1$, with 0 being the lowest possible answer, and 1 being the highest. 
Table 2: Before the final GSS equation in Table 1

The difference between the two columns is the addition of mastery scale in the second column

When the domain satisfaction variables are then added, we get the final GSS equation shown in Table 1

\begin{tabular}{|c|c|c|c|c|}
\hline \multirow[t]{4}{*}{ D.V: Life satisfaction } & \multicolumn{4}{|c|}{ GSS Sample } \\
\hline & \multirow{3}{*}{$\begin{array}{c}\# \text { obs }=9949 \\
F(33,3536)=59.24 \\
\text { Coef. }\end{array}$} & \multirow[b]{3}{*}{ Std. Err. } & \multirow{2}{*}{\multicolumn{2}{|c|}{$\begin{array}{l}\text { of obs }=9949 \\
F(34.3535)=60.46\end{array}$}} \\
\hline & & & & \\
\hline & & & Coef. & Std. Err. \\
\hline Mastery scale, with income effect subtracted & & & 1.204 & 0.101 \\
\hline Job satisfaction, with income effect subtracted & 0.241 & 0.009 & 0.233 & 0.009 \\
\hline Log of total household income & 0.142 & 0.029 & 0.167 & 0.030 \\
\hline Log of avg. household income in census tract & -0.168 & 0.040 & -0.164 & 0.040 \\
\hline Self-perceived health status, scaled 1 to 5 & 0.322 & 0.016 & 0.302 & 0.016 \\
\hline Gender: Male & -0.055 & 0.025 & -0.055 & 0.025 \\
\hline Age Group: 25 34 & -0.221 & 0.057 & -0.210 & 0.057 \\
\hline Age Group: 35 44 & -0.370 & 0.057 & -0.348 & 0.058 \\
\hline Age Group: 45 54 & -0.427 & 0.061 & -0.379 & 0.062 \\
\hline Age Group: 55 64 & -0.349 & 0.066 & -0.299 & 0.067 \\
\hline Age Group: 65 up & -0.167 & 0.151 & -0.106 & 0.152 \\
\hline Marital Status: Married & 0.273 & 0.035 & 0.283 & 0.035 \\
\hline Marital Status: As Married & 0.156 & 0.042 & 0.157 & 0.042 \\
\hline Marital Status: Divorced & -0.234 & 0.065 & -0.245 & 0.065 \\
\hline Marital Status: Separated & -0.069 & 0.051 & -0.092 & 0.051 \\
\hline Marital Status: Widowed & -0.169 & 0.109 & -0.175 & 0.109 \\
\hline Education: High school & -0.207 & 0.057 & -0.215 & 0.057 \\
\hline Education: Between & -0.185 & 0.050 & -0.225 & 0.050 \\
\hline Education: University Degree & -0.259 & 0.055 & -0.316 & 0.055 \\
\hline Contacts with family member outside household & 0.211 & 0.043 & 0.214 & 0.043 \\
\hline Contacts with friends & 0.131 & 0.053 & 0.121 & 0.053 \\
\hline Contacts with neighbours & -0.002 & 0.046 & -0.006 & 0.046 \\
\hline Number of membership or extent of activity & 0.043 & 0.032 & 0.006 & 0.032 \\
\hline Trust in general & -0.024 & 0.029 & -0.067 & 0.030 \\
\hline Trust in neighbours & 0.126 & 0.017 & 0.120 & 0.017 \\
\hline Trust in police / Confidence in police & 0.308 & 0.060 & 0.285 & 0.061 \\
\hline Importance of religion & 0.105 & 0.048 & 0.119 & 0.048 \\
\hline Frequency of attending religious services & -0.090 & 0.053 & -0.078 & 0.054 \\
\hline Immigrant & -0.035 & 0.038 & -0.008 & 0.038 \\
\hline
\end{tabular}




\begin{tabular}{|c|c|c|c|c|}
\hline Ethnic: Aboriginal & 0.145 & 0.084 & 0.126 & 0.084 \\
\hline Ethnic: Chinese & -0.090 & 0.082 & -0.030 & 0.082 \\
\hline Ethnic: South Asia & -0.185 & 0.109 & -0.128 & 0.111 \\
\hline Ethnic: Others non-major European countries & -0.016 & 0.041 & -0.003 & 0.041 \\
\hline Living in non-tracted area & 0.000 & 0.031 & 0.009 & 0.031 \\
\hline /cut1 & -1.284 & 0.505 & -1.208 & 0.505 \\
\hline /cut2 & -0.853 & 0.491 & -0.763 & 0.490 \\
\hline /cut3 & -0.488 & 0.487 & -0.386 & 0.485 \\
\hline /cut4 & -0.244 & 0.487 & -0.136 & 0.486 \\
\hline /cut5 & 0.491 & 0.487 & 0.617 & 0.486 \\
\hline /cut6 & 0.960 & 0.488 & 1.094 & 0.488 \\
\hline /cut7 & 1.840 & 0.491 & 1.988 & 0.490 \\
\hline /cut8 & 2.931 & 0.494 & 3.093 & 0.493 \\
\hline /cut9 & 3.736 & 0.496 & 3.904 & 0.495 \\
\hline
\end{tabular}


Table 3: Job Satisfaction Equations of ESC and GSS with and without mastery scale Survey Ordered Probit

\begin{tabular}{|c|c|c|c|c|c|c|}
\hline \multirow[b]{2}{*}{ D.V. Job satisfaction } & \multicolumn{2}{|c|}{ ESC Sample } & \multicolumn{4}{|c|}{ GSS Sample } \\
\hline & $\begin{array}{r}\text { Number of obs }=2 \\
F(18, \quad 937)=45 . \\
\text { Coef. }\end{array}$ & $\begin{array}{l}32 \\
62 \\
\text { Std. Err. }\end{array}$ & $\begin{array}{l}\text { obs\# } 11 \\
\text { F( } 12,3 \\
\text { Coef. }\end{array}$ & $\begin{array}{l}85 ; \\
93)=64.15 \\
\text { Std. Err. }\end{array}$ & $\begin{array}{l}\text { obs\# } 110 \\
\mathrm{~F}\left(\begin{array}{l}13,3 \\
\text { Coef. }\end{array}\right.\end{array}$ & $\begin{array}{l}\text { 2) }=66.74 \\
\text { Std. Err. }\end{array}$ \\
\hline Mastery scale, with income effect subtracted (GSS only) & & & & & 0.829 & 0.090 \\
\hline Log of personal income & 0.187 & 0.042 & 0.102 & 0.021 & 0.077 & 0.021 \\
\hline Log of other family members' income & 0.016 & 0.015 & & & & \\
\hline Job: Makes own decision (ESC only) & 0.190 & 0.087 & & & & \\
\hline Job: Requires skill(ESC only) & 0.307 & 0.105 & & & & \\
\hline Job: Have enough time(ESC only) & 0.425 & 0.087 & & & & \\
\hline Job: Free of conflicting demands(ESC only) & 0.299 & 0.082 & & & & \\
\hline Job: Has variety of tasks(ESC only) & 0.222 & 0.113 & & & & \\
\hline Job: Trust in management(ESC), or Trust in co-workers(GSS) & 3.491 & 0.150 & 1.017 & 0.056 & 0.949 & 0.057 \\
\hline Self-perceived health status, scaled 1 to 5 & 0.062 & 0.032 & -0.036 & 0.025 & -0.029 & 0.025 \\
\hline Gender: Male & -0.151 & 0.049 & 0.237 & 0.014 & 0.216 & 0.014 \\
\hline Age Group: 25 34 & -0.165 & 0.105 & -0.039 & 0.052 & -0.015 & 0.052 \\
\hline Age Group: 35 44 & -0.289 & 0.101 & -0.089 & 0.052 & -0.055 & 0.052 \\
\hline Age Group: 45 54 & -0.139 & 0.106 & -0.080 & 0.055 & -0.030 & 0.055 \\
\hline Age Group: 55 64 & 0.069 & 0.137 & 0.026 & 0.058 & 0.084 & 0.059 \\
\hline Age Group: 65 up & -0.019 & 0.276 & 0.325 & 0.119 & 0.391 & 0.119 \\
\hline Education: High school & -0.111 & 0.105 & -0.273 & 0.051 & -0.281 & 0.051 \\
\hline Education: Between & -0.153 & 0.094 & -0.322 & 0.041 & -0.354 & 0.041 \\
\hline Education: University Degree & -0.251 & 0.093 & -0.340 & 0.045 & -0.382 & 0.045 \\
\hline /cut1 & 1.808 & 0.443 & -0.002 & 0.207 & 0.172 & 0.205 \\
\hline /cut2 & 2.289 & 0.444 & 0.251 & 0.205 & 0.427 & 0.203 \\
\hline /cut3 & 2.746 & 0.441 & 0.496 & 0.206 & 0.674 & 0.204 \\
\hline /cut4 & 3.225 & 0.435 & 0.694 & 0.206 & 0.874 & 0.204 \\
\hline /cut5 & 3.817 & 0.441 & 1.165 & 0.206 & 1.350 & 0.204 \\
\hline /cut6 & 4.291 & 0.442 & 1.503 & 0.207 & 1.690 & 0.205 \\
\hline /cut7 & 5.146 & 0.444 & 2.098 & 0.207 & 2.289 & 0.205 \\
\hline /cut8 & 6.258 & 0.452 & 2.881 & 0.208 & 3.077 & 0.206 \\
\hline /cut9 & 6.897 & 0.454 & 3.454 & 0.210 & 3.653 & 0.208 \\
\hline
\end{tabular}


Table 4: Estimated Compensating Differentials and their Standard Errors

Panel a: Compensating differentials for non-financial job satisfaction, ESC and GSS

Std Error of the ratio $\%$ income equivalence

\begin{tabular}{|l|l|}
\hline & of a one-unit increase,
\end{tabular}

Using the Using the out of a ten-point scale

Delta Bootstrap in non-financial jobsatis

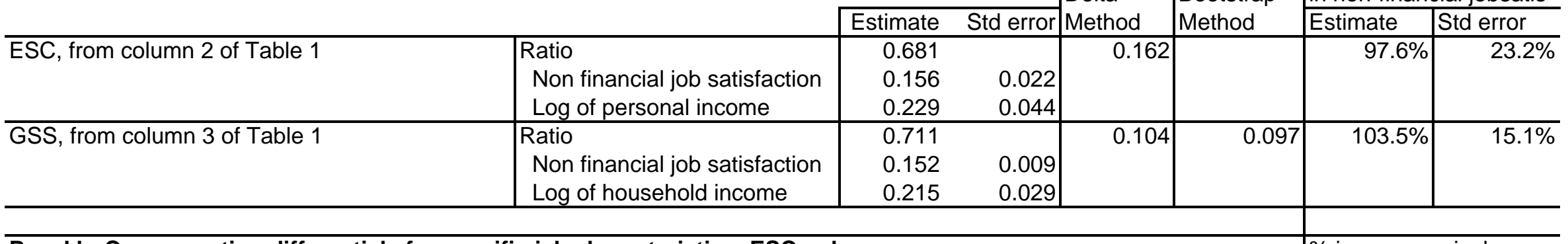

Panel b: Compensating differentials for specific job characteristics; ESC only

$\%$ income equivalence

Std Error of the ratio of a jump that equals

Using the Using the to 1/10 of the bottom-to-

Delta $\quad$ Bootstrap -top difference

ESC, from column 1 of Table 1

ESC, from column 1 of Table 1

ESC, from column 1 of Table 1

ESC, from column 1 of Table 1

ESC, from column 1 of Table 1

ESC, from column 1 of Table 1

\begin{tabular}{|c|c|c|c|c|c|c|}
\hline & 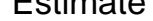 & Gen criver & \multirow{4}{*}{0.578} & & \\
\hline Ratio & -0.778 & & & & \multirow{3}{*}{\multicolumn{2}{|c|}{ statistically insignificant }} \\
\hline Job: Makes own decision (ESC & -0.156 & 0.115 & & & & \\
\hline Log of personal income & 0.200 & 0.047 & & & & \\
\hline Ratio & 1.701 & & \multirow[t]{3}{*}{0.797} & & \multirow[t]{3}{*}{$18.5 \%$} & \multirow[t]{3}{*}{$8.7 \%$} \\
\hline Job: Requires skill(ESC only) & 0.340 & 0.120 & & & & \\
\hline Log of personal income & 0.200 & 0.047 & & & & \\
\hline Ratio & 1.048 & & \multirow[t]{3}{*}{0.517} & & \multirow[t]{3}{*}{$11.0 \%$} & \multirow[t]{3}{*}{$5.4 \%$} \\
\hline Job: Have enough time(ESC on & 0.210 & 0.094 & & & & \\
\hline Log of personal income & 0.200 & 0.047 & & & & \\
\hline Ratio & 0.697 & 0.492 & \multirow[t]{3}{*}{0.492} & & \multirow{3}{*}{\multicolumn{2}{|c|}{ statistically insignificant }} \\
\hline Job: Free of conflicting demand & 0.139 & 0.091 & & & & \\
\hline Log of personal income & 0.200 & 0.047 & & & & \\
\hline Ratio & 1.884 & & \multirow[t]{3}{*}{0.823} & & \multirow[t]{3}{*}{$20.7 \%$} & \multirow[t]{3}{*}{$9.1 \%$} \\
\hline Job: Has variety of tasks(ESC & 0.377 & 0.131 & & & & \\
\hline Log of personal income & 0.200 & 0.047 & & & & \\
\hline Ratio & 3.093 & & \multirow[t]{3}{*}{0.889} & & \multirow[t]{3}{*}{$36.2 \%$} & \multirow[t]{3}{*}{$10.4 \%$} \\
\hline Job: Trust in management(ESC & 0.619 & 0.121 & & & & \\
\hline Log of personal income & 0.200 & 0.047 & & & & \\
\hline
\end{tabular}


Table 5: Compensating Differentials for Workplace Trust; GSS, EDS, and ESC

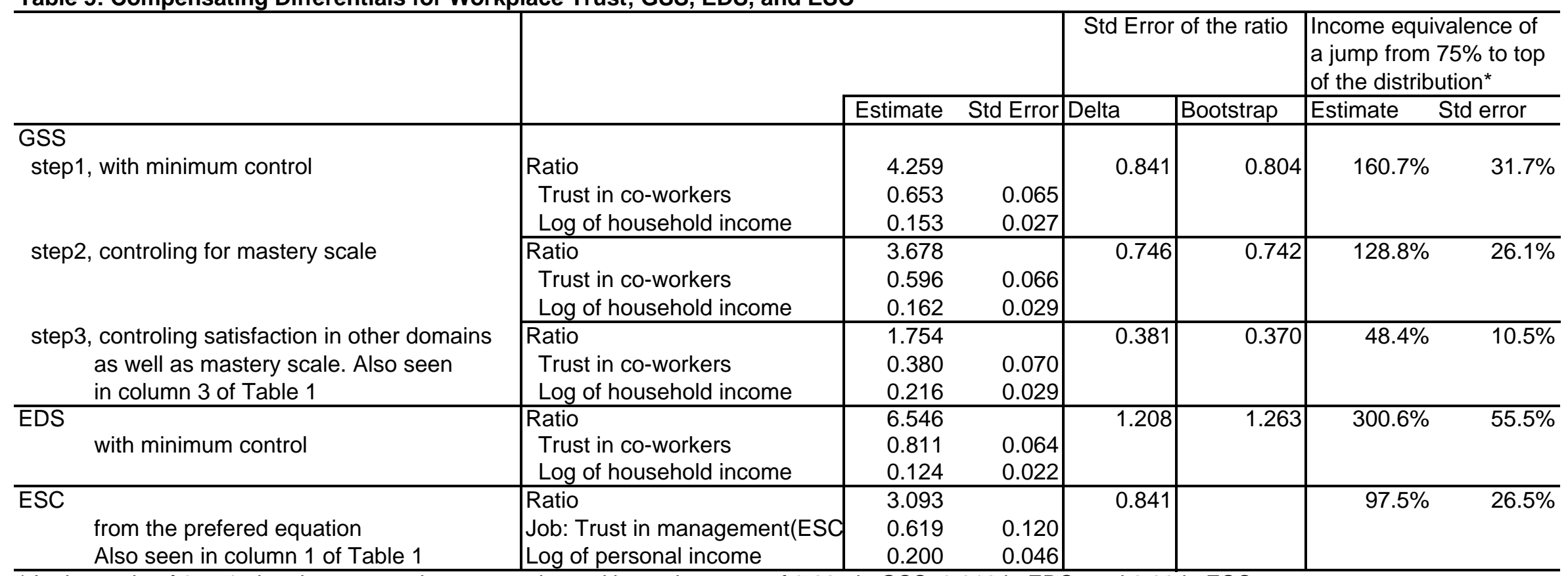

* In the scale of 0 to 1 , the changes are best approximated by an increase of 0.225 in GSS, 0.212 in EDS, and 0.22 in ESC 
Table 6: Comparing Direct and Indirect Effects of Job Characteristics; ESC

Direct and indirect effects

Indirect effect

Supplementary direct

Sum of

from reduced form

mediated through

effect in equation that

2nd and 3rd

regressions*

job satisfaction**

including job satisfaction ${ }^{\star * *}$

column

\begin{tabular}{l|r}
\hline Job: Makes own decision & -0.156 \\
Job: Requires skill & 0.340 \\
Job: Have enough time & 0.210 \\
Job: Free of conflicting demands & 0.139 \\
Job: Has variety of tasks & 0.377 \\
Job: Trust in management & 0.619
\end{tabular}

0.044

$-0.176$

$-0.131$

0.340

0.061

0.312

0.210

0.070

0.161

0.230

0.377

0.049

0.107

0.156

Job: Trust in management

0.742

0.352

0.367

* From column 1 of Table 1

** Essentially these are products of job attributes' coefficients in job satisfation equation and J.S. 's coefficient in life satisfaction equation

***The regression is not shown here due to space limit, but it is available upon request

\section{Table 7: Redo Table 1's GSS regression, excluding respondents whose answer to satisfaction questions has little variation}

\begin{tabular}{|c|c|c|c|}
\hline & Full Sample & Variation*>2 & Variation*>3 \\
\hline Job satisfaction, with income effect subtracted & $0.152[0.009]$ & $0.128[0.009]$ & $0.124[0.009]$ \\
\hline Log of total household income & 0.215 [0.029] & $0.188[0.032]$ & 0.185 [0.033] \\
\hline sample size & 9949 & 7721 & 6871 \\
\hline & Variation ${ }^{\star}>4$ & $\operatorname{VarCoef}{ }^{\star *}>0.1$ & VarCoef $>0.15$ \\
\hline Job satisfaction, with income effect subtracted & $0.107[0.009]$ & $0.135[0.009]$ & $0.097[0.010]$ \\
\hline Log of total household income & $0.175[0.033]$ & $0.184[0.031]$ & $0.168[0.039]$ \\
\hline sample size & 5613 & 6482 & 4202 \\
\hline
\end{tabular}

* Variation = Variation of Lsatis and the four domain satisfactions

** VarCoef =Standard deviation of the five satisfaction measures / Average of the five measures 


\section{Appendix Tables}

A-1: First Stage Regression of Job satisfaction in ESC and GSS, Survey Linear Regression

\section{(Survey Linear Regression)}

\begin{tabular}{|c|c|c|c|c|}
\hline \multirow[b]{2}{*}{ D.V: Job satisfaction } & \multicolumn{2}{|c|}{ ESC Sample } & \multicolumn{2}{|c|}{ GSS Sample } \\
\hline & $\begin{array}{r}\begin{array}{r}\text { Number of obs } \\
\text { R-squared=0.5 } \\
\text { Coef. }\end{array} \\
\end{array}$ & Std. Err. & $\begin{array}{c}\text { Number of } \\
\text { F( } 37, \quad 35 \\
\text { Coef. }\end{array}$ & $\begin{array}{l}\text { bs }=9949 \\
2)=51.57 \\
\text { Std. Err. }\end{array}$ \\
\hline \multicolumn{3}{|l|}{ Mastery scale, with income effect subtracted (GSS only) } & 0.995 & 0.157 \\
\hline Log of personal income & 0.287 & 0.058 & 0.187 & 0.035 \\
\hline Log of other family members' income & 0.034 & 0.022 & & \\
\hline Log of avg. household income in census tract & -0.192 & 0.103 & 0.016 & 0.067 \\
\hline Satisfaction with health (GSS only) & & & 0.304 & 0.021 \\
\hline \multicolumn{3}{|c|}{ Satisfaction with the way other time spent(GSS only) } & 0.047 & 0.013 \\
\hline \multicolumn{3}{|c|}{ Satisfaction with financial situation, with income effect subtracted(GSS only) } & 0.217 & 0.014 \\
\hline Job: Makes own decision (ESC only) & 0.284 & 0.136 & & \\
\hline Job: Requires skill(ESC only) & 0.393 & 0.148 & & \\
\hline Job: Have enough time(ESC only) & 0.449 & 0.125 & & \\
\hline Job: Free of conflicting demands(ESC only) & 0.317 & 0.114 & & \\
\hline Job: Has variety of tasks(ESC only) & 0.096 & 0.166 & & \\
\hline Job: Trust in management(ESC), or Trust in co-wd & 4.761 & 0.172 & 1.435 & 0.119 \\
\hline Self-perceived health status, scaled 1 to 5 & 0.035 & 0.043 & -0.080 & 0.030 \\
\hline Gender: Male & -0.155 & 0.068 & -0.074 & 0.042 \\
\hline Age Group: 25 34 & -0.213 & 0.144 & 0.005 & 0.093 \\
\hline Age Group: 35 44 & -0.343 & 0.152 & -0.065 & 0.095 \\
\hline Age Group: 45 54 & -0.179 & 0.157 & -0.016 & 0.099 \\
\hline Age Group: 55 64 & 0.024 & 0.181 & 0.093 & 0.105 \\
\hline Age Group: 65 up & 0.189 & 0.356 & 0.335 & 0.180 \\
\hline Marital Status: Married & -0.025 & 0.106 & 0.074 & 0.053 \\
\hline Marital Status: As Married & -0.179 & 0.141 & 0.185 & 0.068 \\
\hline Marital Status: Divorced & -0.045 & 0.176 & 0.043 & 0.116 \\
\hline Marital Status: Separated & -0.057 & 0.184 & 0.031 & 0.087 \\
\hline Marital Status: Widowed & -0.316 & 0.463 & 0.083 & 0.163 \\
\hline Education: High school & -0.205 & 0.137 & -0.224 & 0.083 \\
\hline Education: Between & -0.177 & 0.133 & -0.255 & 0.069 \\
\hline Education: University Degree & -0.295 & 0.131 & -0.237 & 0.075 \\
\hline Contacts with family member outside household & 0.083 & 0.116 & 0.011 & 0.068 \\
\hline Contacts with friends & 0.414 & 0.137 & 0.277 & 0.084 \\
\hline
\end{tabular}


Contacts with neighbours

Number of membership or extent of activity

Trust in general

Trust in neighbours

Trust in police / Confidence in police

Importance of religion

Frequency of attending religious services

Immigrant(GSS only)

Ethnic: Aboriginal(GSS only)

Ethnic: Chinese(GSS only)

Ethnic: South Asia(GSS only)

Ethnic: Others non-major European countries (GSS only)

Living in non-tracted area(GSS only)

Constant

\begin{tabular}{rr|rr}
0.098 & 0.123 & 0.140 & 0.069 \\
0.016 & 0.021 & -0.119 & 0.050 \\
0.029 & 0.074 & -0.092 & 0.044 \\
0.008 & 0.110 & -0.062 & 0.027 \\
-0.163 & 0.141 & 0.224 & 0.093 \\
0.247 & 0.132 & 0.183 & 0.073 \\
-0.087 & 0.128 & 0.066 & 0.075 \\
& & 0.136 & 0.062 \\
& & 0.181 & 0.120 \\
& & -0.258 & 0.119 \\
& & -0.257 & 0.152 \\
& & -0.013 & 0.060 \\
1.956 & 1.125 & -0.021 & 0.048 \\
& & 1.668 & 0.757 \\
\hline
\end{tabular}




\section{A-2: Regressing Personal Income on workplace variables, ESC and GSS Survey Linear Regression}

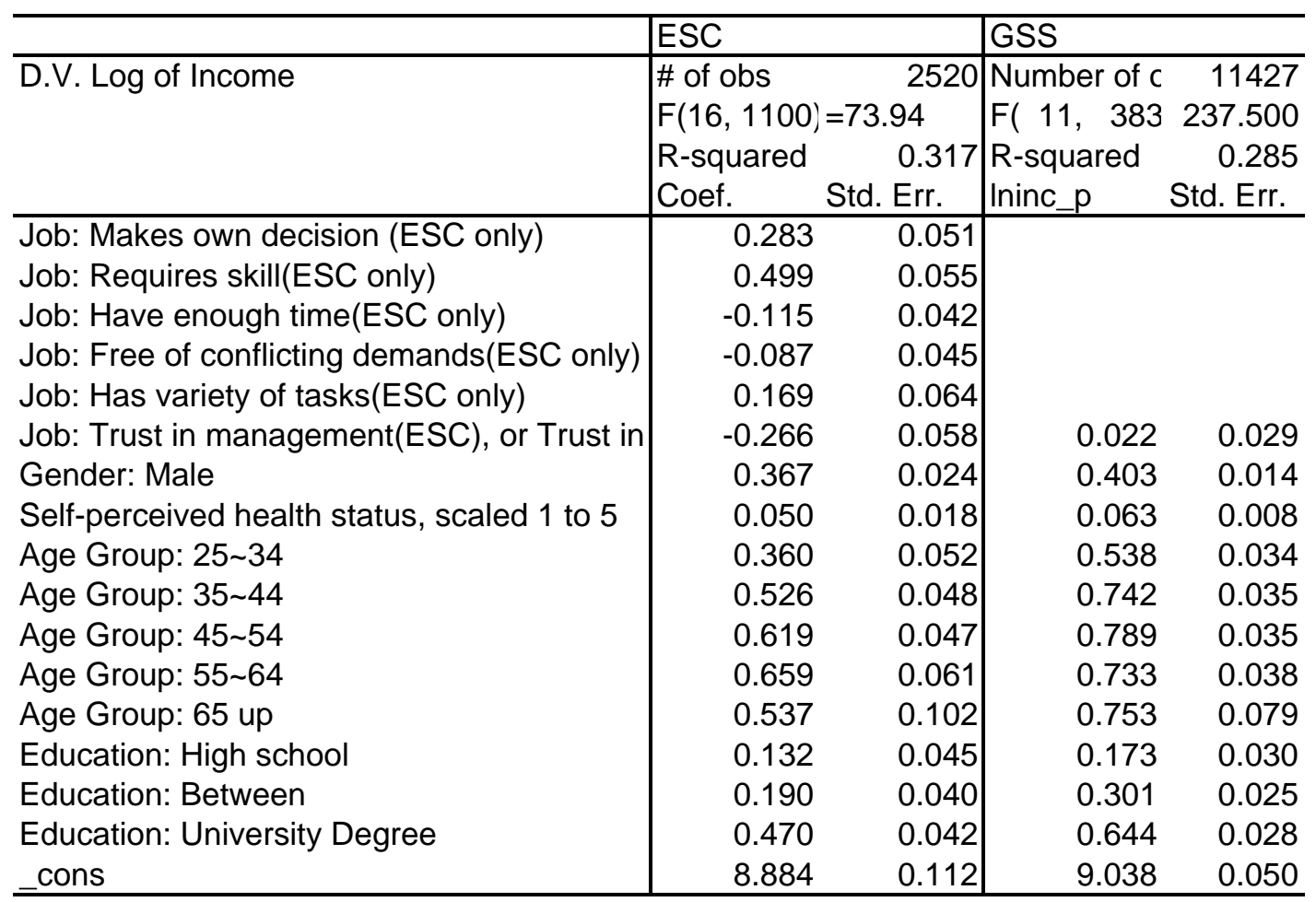

\section{A-3: Correlation Tables}

a. ESC

Life Log of Log of Log of Job Job: Job: Job: satisfaction personal household Avg. CT Satisfaction Make requires have time

Life satisfaction income income Income decision skill

Log of personal incom

Log of household inco

1.00

Log of Average Censı

$0.11 \quad 1.00$

Job Satisfaction

0.19

0.58

0.04

0.18

$0.10 \quad 0.35$

0.26

Job: Makes own decis

0.06

0.44

0.27

1.00

0.35

Job: Requires skill(ES

0.08

0.48

0.36

0.03

1.00

Job: Have enough tim

0.06

0.20

0.11

0.74

1.00

Job: Free of conflictinc

0.08

0.25

0.17

0.06

0.74

0.84

1.00

0.07

0.22

0.33

0.02

0.69

0.64

0.61

1.00

Job: Has variety of tas

0.10

0.25

0.62

0.56

0.56

0.71

Job: Trust in managen

0.32

0.10

0.77

0.84

0.86

0.68

Job: free f| Job: have $v$ Trust in Management

Job: free from conflicting demand $\quad 1.00$

Job: have variety

0.59

0.65

1.00

0.77

1.00

b. GSS

Life satisfaction

Job Satisfaction

Mastery Scale

Log of personal income

Trust in co-workers
Life satis. Job Satis. Mastery Log of persc Trust in co-workers

1.00

$0.43 \quad 1.00$

$0.24 \quad 0.14$

$0.05 \quad 0.08$

$0.21 \quad 0.25$
1.00

0.16

0.15
1.00

$0.06 \quad 1.00$ 


\section{A-4: Distributions}

Distribution of reported life satisfaction, GSS

Job

1
2
3
4
5
6
7
8
9

10
$\%$ distribution

0.68

0.52

0.83

1.14

5.72

5.78

17.54

31.56

19.27

16.95

Distribution of reported job satisfaction, GSS

Job Satisfaction $\quad \%$ distribution

1
2
3
4
5
6
7
8
9

1.33

1

1.62

1.93

7.44

7.6

18.49

28.39

16

16.2

$\begin{array}{lc}\begin{array}{l}\text { Distribution of reported trust in colleagues } \\ \text { GSS } \\ \text { trust in }\end{array} \\ \text { colleagues } & \text { \% distribution } \\ 0 & \\ 0.25 & 3.69 \\ 0.5 & 5.96 \\ 0.75 & 24.91 \\ 1 & 37.7 \\ \text { EDS } & 27.73 \\ \text { trust in } & \\ \text { colleagues } & \\ 0 & \text { \% distribution } \\ 0.25 & \\ 0.5 & 2.21 \\ 0.75 & 5.21 \\ 1 & 24.76 \\ \end{array}$

Distribution of reported life satisfaction, ESC

Job Satisfaction $\quad \%$ distribution

\section{1}

0.8

0.44

0.51

1.38

4.63

5.14

18.22

31.78

$\begin{array}{ll}9 & 17.71 \\ 10 & 19.39\end{array}$

Distribution of reported job satisfaction, ESC

Job Satisfaction \% distribution

$1 \quad 1.31$

$2 \quad 1.06$

$3 \quad 2.26$

$4 \quad 3.46$

$\begin{array}{lr}4 & 7.4\end{array}$

$\begin{array}{lr}5 & 9.26\end{array}$

$7 \quad 22.16$

$8 \quad 29.05$

$9 \quad 11.66$

$10 \quad 12.39$ 


\section{Distribution of other job characteristics in ESC}

a)..job requires a high level of skill

\begin{tabular}{cccc} 
j_skill | & Freq. & Percent & Cum. \\
- \hdashline $0 \mid$ & 108 & 3.45 & 3.45 \\
$.33 \mid$ & 298 & 9.51 & 12.96 \\
$.67 \mid$ & 1,100 & 35.12 & 48.08 \\
$1 \mid$ & 1,626 & 51.92 & 100.00 \\
-------- &
\end{tabular}

c)..job is free from conflicting demands

$\begin{array}{cccc}\text { j_free | } & \text { Freq. } & \text { Percent } & \text { Cum. } \\ -0 \mid & 540 & 17.26 & 17.26 \\ .33 \mid & 963 & 30.78 & 48.03 \\ .67 \mid & 1,002 & 32.02 & 80.06 \\ 1 \mid & 624 & 19.94 & 100.00 \\ -------------- & \end{array}$

b)..job has a variety of tasks

\begin{tabular}{|c|c|c|c|}
\hline j_varie | & Freq. & Percent & Cum \\
\hline 01 & 66 & 2.11 & 2.11 \\
\hline $.33 \mid$ & 170 & 5.43 & 7.54 \\
\hline $.67 \mid$ & 796 & 25.42 & 32.95 \\
\hline $1 \mid$ & 2,100 & 67.05 & 100.00 \\
\hline Total | & 3,132 & 100.00 & \\
\hline
\end{tabular}

d)..You have enough time to get the job done

\begin{tabular}{cccc} 
j_time & Freq. & Percent & Cum. \\
$-0 \mid$ & 299 & 9.55 & 9.55 \\
$.33 \mid$ & 514 & 16.41 & 25.96 \\
$.67 \mid$ & 1,193 & 38.09 & 64.05 \\
$1 \mid$ & 1,126 & 35.95 & 100.00 \\
- \hdashline--------
\end{tabular}

e)..job allows you to make a lot of decisions on your own

j_owndec| Freq. Percent Cum.

\begin{tabular}{cccc}
$0 \mid$ & 148 & 4.73 & 4.73 \\
$.33 \mid$ & 306 & 9.77 & 14.50 \\
$.67 \mid$ & 938 & 29.95 & 44.44 \\
$1 \mid$ & 1,740 & 55.56 & 100.00 \\
--------- & \\
Total | & 3,132 & \multicolumn{3}{c}{100.00}
\end{tabular}




\section{A-5: Exact Wording in the Survey \\ Vairble Name Scale Variable Names in raw data}

Life Saisfaction

Isatis 1 10 lifesat1

Now a question about life satisfaction. On a scale of 1-10 where ONE means dissatisfied and TEN means satisfied, all things considered how satisfied are you with your life as a whole these days?

Job Satisfaction
jobsat_1
$1 \sim 10$
jobsat_1

On a scale of 1 to 10, where 1 means very poor and 10 means very good, on average, how would you rate job satisfaction for workers at your workplace?

\section{Workplace Trust}

emp_tr zero to one jobsat_3

Using the same scale, how would you rate the level of trust that workers have in management at your workplace?

\section{Job Characteristics}

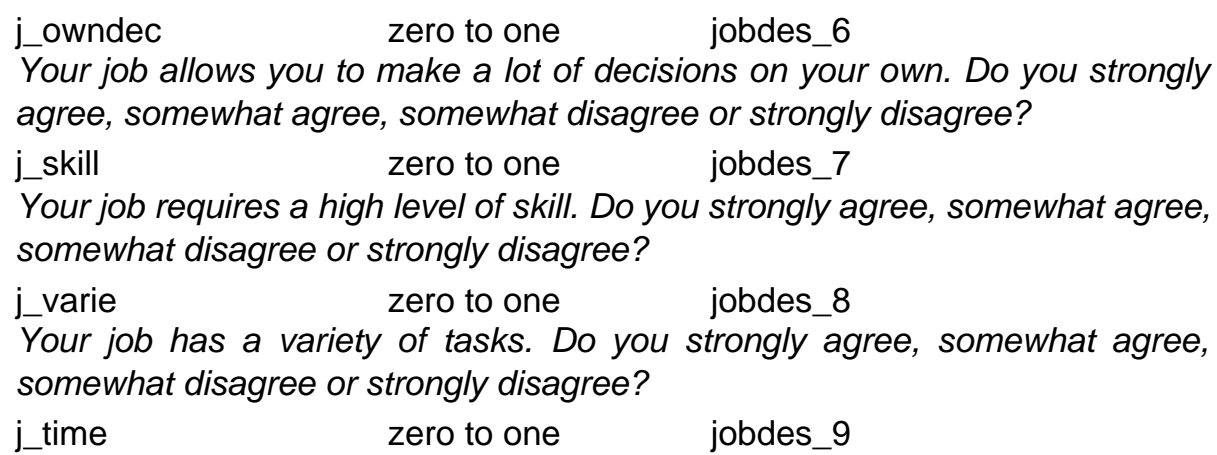

You have enough time to get the job done. Do you strongly agree, somewhat agree, somewhat disagree or strongly disagree?

j_free zero to one jobdes10

Your job is free from conflicting demands. Do you strongly agree, somewhat agree, somewhat disagree or strongly disagree?

\section{Life Satisfaction}

Lsatis $\quad 1 \sim 10$

Please rate your feelings about them, using a scale of 1 to 10 where 1 means "Very dissatisfied" and 10 means "Very satisfied". What about:

...your life as a whole right now?

Job Satisfaction

jobsatis $\quad 1 \sim 10$

Please rate your feelings about them, using a scale of 1 to 10 where 1 means "Very dissatisfied" and 10 means "Very satisfied". What about

...your job or your main activity?

\section{Other Domains of Satisfaction}

Please rate your feelings about them, using a scale of 1 to 10 where 1 means

"Very dissatisfied" and 10 means "Very satisfied". What about: 
satis_h $\quad$...your health?

satis_ot $\quad$...the way you spend your other time?

satis_fn ...your finances?

Workplace Trust

tr_col zero to one

Using a scale of 1 to 5 where 1 means 'Cannot be trusted at all' and 5 means

'Can be trusted a lot', how much do you trust

people you work with or go to school with?

\section{Mastery Scale}

mastery zero to one

Please tell me if you strongly agree, agree, neither agree nor disagree, disagree, or strongly disagree that:

...you have little control over the things that happen to you.

...there is really no way you can solve some of the problems you have.

...there is little you can do to change many of the important things in your life.

...you often feel helpless in dealing with problems of life

...sometimes you feel that you are being pushed around in life .

...what happens to you in the future mostly depends on you.

...you can do just about anything you really set your mind to.

EDS

\section{Life Satisfaction}

\section{Lsatis}

\section{Ts_Q010}

All things considered, how satisfied are you with your life as a whole these days? 1 measures not satisfied at all and 5 means very satisfied

\section{Workplace Trust}

tr_col

Ts_Q050

Using a scale of 1 to 5 where 1 means cannot be trusted at all and 5 means can be trusted alot, how much do you trust each of the following group of people:

...People that you work with or go to school with 